Araújo, LGS, Norberto, AS, Ferreira, RPS, Mariano, MOH \& Callado, NH. (2020). Evaluation of the efficiency of leachate treatment in a landfill. Research, Society and Development, 9(7): 1-35, e564974466.

\title{
Avaliação da eficiência do tratamento de lixiviado de um aterro sanitário
} Evaluation of the efficiency of leachate treatment in a landfill

Evaluación de la eficiencia de tratamiento de lixiviados de un relleno sanitário

Recebido: 12/05/2020 | Revisado: 14/05/2020 | Aceito: 18/05/2020 | Publicado: 30/05/2020

\section{Liz Geise Santos de Araújo}

ORCID: https://orcid.org/0000-0003-0196-7064

Universidade Federal de Pernambuco, Brasil

E-mail: lizaraujoeng@gmail.com

Alison de Souza Norberto

ORCID: https://orcid.org/0000-0002-4303-4847

Universidade Federal de Pernambuco, Brasil

E-mail: alison_norberto@hotmail.com

Riadny Patrícia de Souza Ferreira

ORCID: https://orcid.org/0000-0003-3229-2717

Universidade Federal de Pernambuco, Brasil

E-mail: riadnypsouzaf@gmail.com

Maria Odete Holanda Mariano

ORCID: https://orcid.org/0000-0001-6027-0510

Universidade Federal de Pernambuco, Brasil

E-mail: odete.mariano@gmail.com

Nélia Henriques Callado

ORCID: https://orcid.org/0000-0002-2393-555X

Universidade Federal de Alagoas, Brasil

E-mail: nelia.callado@yahoo.com.br

\section{Resumo}

O lixiviado é um líquido altamente contaminante, gerado nos aterros sanitários, é um dos principais desafios ambientais, especialmente no que se refere ao seu tratamento, visto que sua composição variada dificulta a escolha de um tratamento continuamente eficiente. Sem o tratamento adequado, este pode ocasionar contaminação do solo e dos recursos hídricos 
superficiais e subterrâneos. Neste contexto, o presente trabalho realizou uma análise da eficiência do tratamento do lixiviado gerado no aterro sanitário da cidade de Maceió-AL, verificando o seu comportamento ao longo dos anos de operação, além de possíveis intercorrências em seu tratamento. As informações foram obtidas através de visitas in loco, bem como por meio de dados secundários disponibilizados pela Superintendência de Limpeza Urbana de Maceió (SLUM). Quanto ao tratamento do lixiviado gerado no aterro sanitário de Maceió, constatou-se muitas variações nas eficiências obtidas durante os períodos, o que demonstra a complexidade no tratamento do lixiviado, especialmente em um aterro em operação, necessitando da adoção de melhorias ao longo do tempo, a fim de obter melhores resultados. Os processos biológicos e de coagulação, floculação e decantação, proporcionaram melhor desempenho no tratamento do lixiviado, obtendo eficiência global média de 98,79\%, 95,45\% e 93,42\% na remoção de demanda bioquímica de oxigênio (DBO), demanda química de Oxigênio (DQO) e Nitrogênio Amoniacal, respectivamente.

Palavras-chave: Lixiviado; Tratamento; Eficiência; Padrões ambientais.

\section{Abstract}

Leachate is a highly contaminating liquid generated in landfills, it is one of the main environmental challenges, especially with regard to its treatment, since its varied composition makes it difficult to choose a continuously efficient treatment. Without the proper treatment, it can cause contamination of the soil and surface and underground water resources. In this context, the present study carried out an analysis of the efficiency of the treatment of leachate generated in the landfill in the city of Maceió-AL, verifying its behavior over the years of operation, in addition to possible complications in its treatment. The information was obtained through on-site visits, as well as through secondary data provided by the Superintendency of Urban Cleaning of Maceió (SLUM). As for the treatment of leachate generated in the landfill in Maceió, there were many variations in the efficiencies obtained during the periods, which demonstrates the complexity in the treatment of leachate, especially in a landfill in operation, requiring the adoption of improvements over time. in order to get better results. The biological and coagulation, flocculation and decantation processes provided better performance in the treatment of leachate, obtaining an average global efficiency of $98.79 \%$, $95.45 \%$ and $93.42 \%$ in removing biochemical oxygen demand (BOD), demand chemical oxygen (COD) and Ammoniacal Nitrogen, respectively.

Keywords: Leachate; Treatment; Efficiency; Environmental standards. 


\section{Resumen}

El lixiviado es un líquido altamente contaminante generado en los vertederos, es uno de los principales desafíos ambientales, especialmente en lo que respecta a su tratamiento, ya que su composición variada dificulta la elección de un tratamiento eficiente de forma continua. Sin el tratamiento adecuado, puede contaminar el suelo y los recursos hídricos superficiales y subterráneos. En este contexto, el presente estudio realizó un análisis de la eficiencia del tratamiento del lixiviado generado en el vertedero de la ciudad de Maceió-AL, verificando su comportamiento a lo largo de los años de operación, además de posibles complicaciones en su tratamiento. La información se obtuvo a través de visitas in situ, así como a través de datos secundarios proporcionados por la Superintendencia de Limpieza Urbana de Maceió (SLUM). En cuanto al tratamiento del lixiviado generado en el vertedero en Maceió, hubo muchas variaciones en las eficiencias obtenidas durante los períodos, lo que demuestra la complejidad en el tratamiento del lixiviado, especialmente en un vertedero en operación, que requiere la adopción de mejoras a lo largo del tiempo. para obtener mejores resultados Los procesos biológicos y de coagulación, floculación y decantación proporcionaron un mejor desempeño en el tratamiento de lixiviados, obteniendo una eficiencia global promedio de $98.79 \%$, 95.45\% y 93.42\% en la eliminación de la demanda bioquímica de oxígeno (DBO). demanda oxígeno químico (DQO) y nitrógeno amoniacal, respectivamente.

Palabras clave: Lixiviado; Tratamiento; Eficiencia; Estándares ambientales.

\section{Introdução}

A geração de lixiviados é um importante problema ambiental que é gerado por aterros de resíduos sólidos urbanos (RSU) (Zegzouti et al., 2019). Os lixiviados de aterros de RSU são produzidos quando a água da chuva percola através dos resíduos depositados no aterro, carreando entre os subprodutos de matéria orgânica e demais substâncias depositadas no aterro. As características qualitativas e quantitativas do lixiviado mudam com a idade de um aterro, tipo de resíduos em aterros, métodos de aterro (isto é, método de compactação, recirculação de lixiviado) e condições climáticas (profundidade da chuva, intensidade, distribuição do tempo, temperatura do ar etc.) (Wojciechowska, 2017)

O lixiviado de aterro sempre contém altas concentrações de metais, como cádmio $(\mathrm{Cd})$, prata $(\mathrm{Ag})$, mercúrio $(\mathrm{Hg})$, chumbo $(\mathrm{Pb})$ e assim por diante. Esses metais pesados estão lixiviando das baterias, cinzas, corantes e assim por diante (Li L., Li Z., Liu \& Song, 2020). Este lixiviado necessita de uma destinação final ou tratamento ambientalmente adequado, pois 
se descartado em locais inadequados podem acarretar em prejuízos à saúde das pessoas, bem como a contaminação do solo e recursos hídricos.

$\mathrm{Na}$ perspectiva ambiental, os aterros sanitários são considerados uma tecnologia adequada para a destinação dos resíduos, porém, se operados de maneira ineficiente, os subprodutos provenientes dos próprios resíduos, tais como o lixiviado e gases, podem acarretar em sérios danos ambientais (Kirmizakis, Tsamoutsoglou, Kayan \& Kalderis, 2014). A operação eficiente de um aterro sanitário, através da impermeabilização das bases, instalação de drenos de coleta de lixiviados e gases, cobertura diária dos resíduos, além da escolha de área viável à sua implantação, configura em maior proteção ao meio ambiente (Oliveira \& Pascal, 2004).

O lixiviado produzido em aterros sanitários se descartado de forma incorreta além contaminar o solo e dos recursos hídricos superficiais e subterrâneos, também emitirá gases que podem provocar consequências ambientais negativas (Youcai \& Ziyang, 2016). Nesse sentido, Renou, Givaudan, Poulain, Dirassouyan e Moulin (2008), discorre que para atender aos padrões de lançamento dos lixiviados em corpos receptores, há necessidade de um adequado tratamento, seja este físico, químico ou biológico, bem como a junção destes.

No município de Maceió, estado de Alagoas, os RSU são coletados por empresas terceirizadas e encaminhados ao Aterro Sanitário da cidade, em operação desde abril de 2010, que recebe uma média diária de 1.500 toneladas. Na área do aterro há uma Estação de Tratamento de Efluentes (ETE) destinada ao tratamento do lixiviado gerado nas células de disposição de resíduos Classe IIA. Estes resíduos sólidos são classificados pela NBR $10004 / 2004$.

Sob esse contexto, o presente trabalho realizou uma análise da eficiência do tratamento do lixiviado gerado no aterro sanitário da cidade de Maceió-AL, verificando o seu comportamento ao longo dos anos de operação, além de possíveis intercorrências em seu tratamento, assim como a proposição de medidas corretivas para o seu adequado funcionamento.

\section{Metodologia}

\section{1 Área de estudo}

A área de estudo foi o aterro sanitário de Maceió, localizado no bairro do Benedito Bentes, parte alta da cidade de Maceió e está sob as coordenadas central de Latitude 
9³3'38.10' 'S e longitude 35\%41'31.49' ' $\mathrm{W}$, possuindo uma área de aproximadamente de 114 ha. As operações da Central de Tratamento de Resíduos de Maceió (CTR/MA), iniciaram-se no dia 30 de abril de 2010, a partir do encerramento do antigo lixão da cidade. Existem dois acessos ao aterro, um pelo litoral norte, planície da cidade e outro pelo bairro do Benedito Bentes, tabuleiro da cidade. Na Figura 1 é apresentado o mapa com a localização da CTR/MA.

Figura 1 - Localização do Aterro Sanitário de Maceió.

(itulo

Fonte: Elaborado pelos Autores (2020).

Todo lixiviado gerado no aterro sanitário de Maceió é encaminhado a ETE (Figura 2), que é composta, atualmente, por sistemas de tratamentos biológicos, que são 1 Lagoa anaeróbia, 1 lagoa de pré-aeração e 1 lagoa aerada; e sistemas físico-químicos, que são floculação e decantação, 1 sistema de filtração por carvão ativado e zeólitas, 1 sistema de nanofiltração e 1 sistema de filtração por zeólitas. 
Figura 2 - Fluxograma da ETE localizada no aterro sanitário de Maceió.

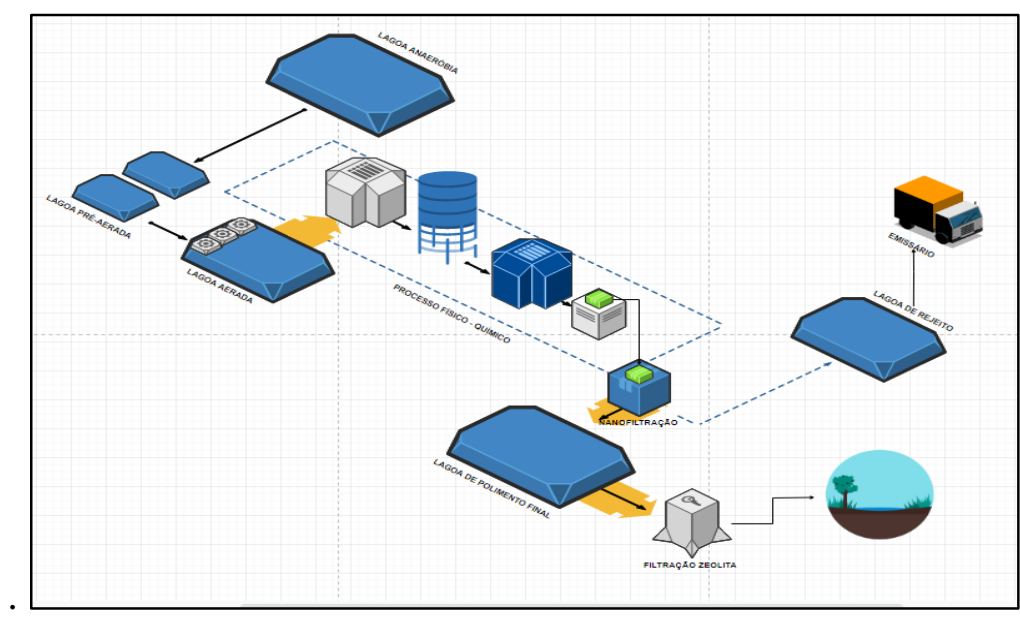

Fonte: Elaborado pelos Autores (2020).

\subsection{Levantamento do sistema de tratamento}

Os itens a seguir apresentam uma breve descrição das etapas de tratamento atualmente utilizadas na Estação de tratamento do aterro sanitário de Maceió.

\section{- Elevatória de lixiviados}

A caixa elevatória é o início do processo, nela é feita a distribuição do lixiviado, objetivando sua entrada nas etapas posteriores da ETE, bem como iniciar possíveis correções necessárias, tais como remoção de espumas.

\section{- Lagoa Anaeróbia}

O sistema anaeróbio é constituído por 1 tanque escavado no solo, com ligação entre eles no nível superior. A fim de evitar contaminação ao solo e águas subterrâneas, estes tanques são impermeabilizados com geomembranas em Polietileno de Alta Densidade (PEAD). O volume total desse tanque é de aproximadamente $5.600 \mathrm{~m}^{3}$. Considerando a média de vazão diária de 243,17 m³ , calculada com as estimativas de vazão obtidas e já citadas nesse estudo, estima-se dessa forma, um Tempo de Detenção Hidráulica (TDH) de 23 dias. Na Figura 3 é apresentada a lagoa anaeróbia utilizada. 
Figura 3 - Lagoa Anaeróbia da ETE do Aterro Sanitário de Maceió.

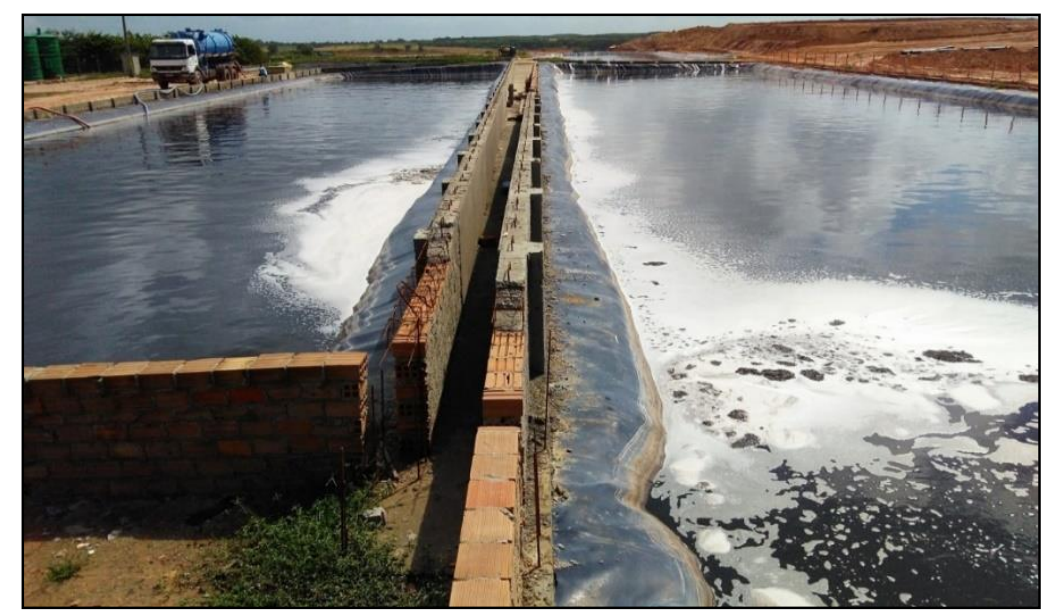

Fonte: Autores (2020).

\section{- Lagoa de Pré-aeração e Lagoa Aerada}

Após o sistema anaeróbio, o lixiviado é encaminhado, através de bombas centrifugas e tubos em PVC, para uma lagoa de pré-aeração, que basicamente possui um sistema de distribuição forçada para mistura do lixiviado, posteriormente, este é encaminhado para a Lagoa Aeróbia Aerada (Figura 4), que é construída em tanque escavado no solo, impermeabilizado com geomembrana PEAD. O volume total do tanque é de aproximadamente $3.000 \mathrm{~m}^{3}$. Considerando a média de vazão de $243,17 \mathrm{~m}^{3}$, calculada com as estimativas de vazão obtidas e já citadas nesse estudo, estima-se dessa forma, um Tempo de Detenção Hidráulica (TDH) de 12 dias. Para a realização da aeração, foram instalados 14 compressores radiais, com interconexão entre os aeradores, havendo, ainda, um sistema de distribuição forçada, para facilitar a mistura do lixiviado dentro do tanque.

Figura 4 - Etapa aeróbia da ETE.

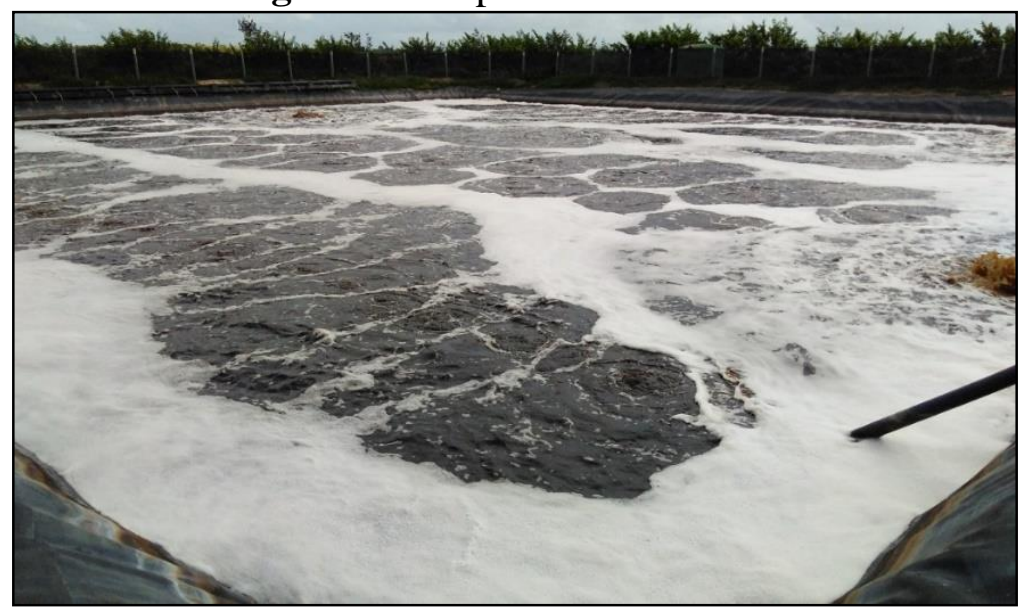

Fonte: Autores (2020). 


\section{- Processo físico-químico: Coagulação, floculação e decantação}

Após a etapa aeróbia, o lixiviado é encaminhado, através de bomba centrífuga e tubos de PVC, ao denominado tanque de equalização, com volume de $28 \mathrm{~m}^{3}$, onde, posteriormente, é enviado ao tanque de mistura por gravidade, com capacidade de $15 \mathrm{~m}^{3}$, construído em fibra de vidro e acabamento em gel isofitálico. Este tanque é composto por dois sistemas de agitação com turbo hélices, que permiti uma mistura homogênea entre o lixiviado e o coagulante utilizado, sendo este o Policloreto de Alumínio, conhecido como PAC. Em seguida, este é conduzido por gravidade para o decantador tipo Dortmund, que tem fundo cônico, com capacidade de $15 \mathrm{~m}^{3}$, construído em fibra de vidro e acabamento em gel isofitálico, que objetiva o processo de separação sólido/liquido por gravidade. Neste sistema, o período de detenção é de aproximadamente 5 minutos. Após o decantador Dortmund, o lixiviado é encaminhado, por gravidade, ao decantador secundário, a fim de remover partículas mais finas ainda presentes no efluente. Após a etapa de decantação, o lixiviado é direcionado à elevatória que irá alimentar o sistema de filtração.

\section{- Filtros de Zeólita}

Após o decantador secundário, o lixiviado é encaminhado, por gravidade, à elevatória, construída em fibra de vidro e com capacidade de $5 \mathrm{~m}^{3}$, que alimenta as bombas centrífugas de alta pressão do sistema de filtragem, onde o sistema de filtragem é composto em duas etapas. A primeira etapa possui 2 filtros construídos em aço inox, com diâmetro de $200 \mathrm{~mm}$, comprimento $4.000 \mathrm{~mm}$ e pressão de trabalho $5 \mathrm{kgf} / \mathrm{cm}^{2}$. Os dois filtros são conectados, de forma paralela, às duas bombas centrífugas, onde funciona apenas um filtro, sendo o outro para caso de manutenção. Nessa primeira etapa, o meio filtrante utilizado é a zeólita mineral, onde os filtros com zeólita são utilizados para a retenção de possíveis metais pesados e surfactantes existentes no efluente.

\section{- Filtros de carvão ativado}

Posteriormente a filtragem por zeólitas, há a segunda etapa da filtração, através de filtros construídos em Aço carbono, que possuem sistema de retrolavagem e operam com pressão de trabalho de $3 \mathrm{kgf} / \mathrm{cm}^{2}$, sendo o meio filtrante utilizado o carvão ativado. Cada filtro tem capacidade de filtragem $15 \mathrm{~m}^{3} / \mathrm{h}$, operado com ambas as bombas. Na Figura 5 é apresentada algumas etapas do sistema físico-químico da ETE em questão. 
Figura 5 - Etapa físico-química da ETE do Aterro Sanitário de Maceió.

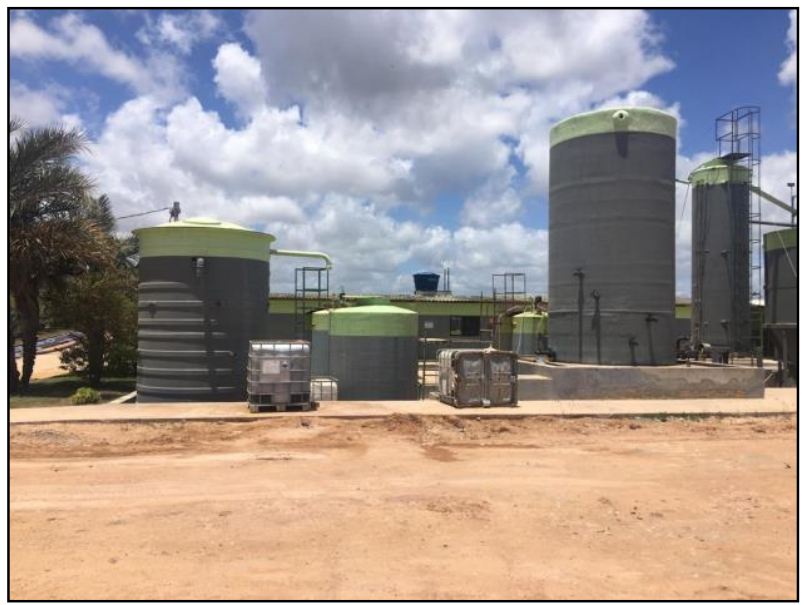

Fonte: Autores (2020).

\section{- Nanofiltração}

A nanofiltração é o processo de filtração realizado por membranas, onde a abertura de seus poros possuem dimensão de 1 nanômetro, e objetiva separar sólidos imiscíveis e solutos que se encontram dissolvidos no efluente, retendo sais com $0,001 \mu \mathrm{m}$ molecular e operando com uma pressão de trabalho entre 10 a 25 Bar. Na Figura 6 é apresentado o sistema de nanofiltração utilizado no aterro sanitário de Maceió.

Figura 6 - Sistema de nanofiltração.

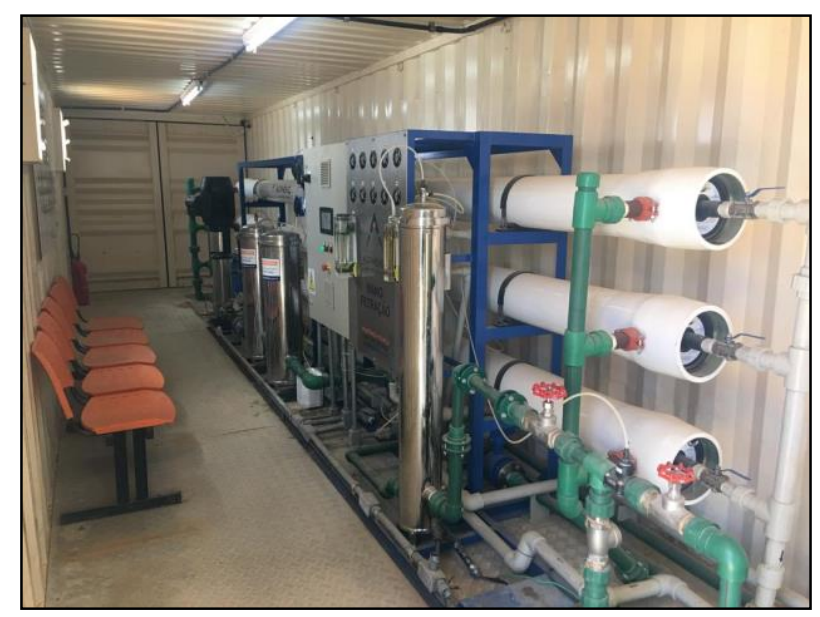

Fonte: Autores (2020)

Posteriormente, o lixiviado tratado é encaminhado a uma lagoa de acumulação (Figura 7) e passa, ainda, por uma nova filtração com zeólitas. Se os parâmetros atenderem ao determinado na outorga de lançamento, o lixiviado tratado é encaminhado ao corpo hídrico receptor (Figura 8), denominado "Riacho Grota da Alegria", que está sob as coordenadas 
09³3'25.49'’S 3541'22.03'’O, onde também são realizadas as análises a fim de que se atenda as determinações expostas na outorga de lançamento, de forma que o lançamento do lixiviado tratado não altere a qualidade das águas superficiais.

Figura 7 - Lagoa de acumulação do lixiviado tratado.

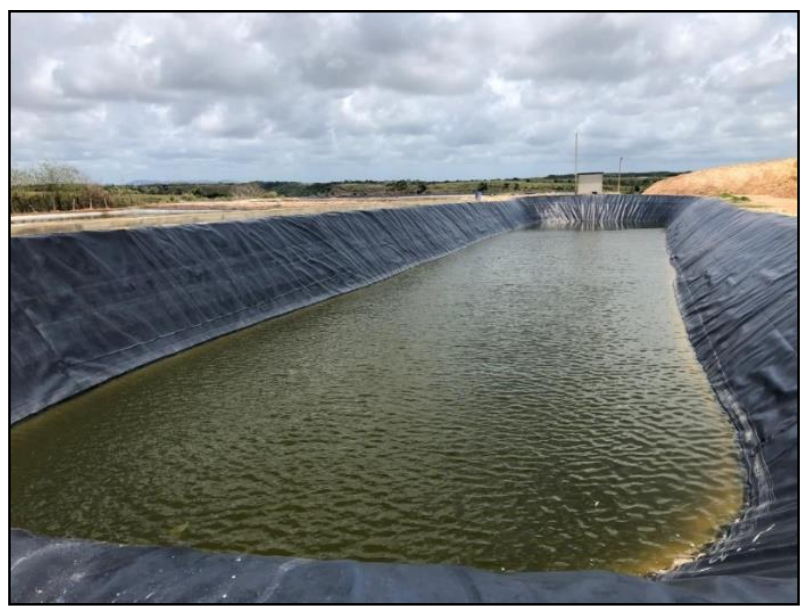

Fonte: Autores (2020)

Figura 8 - Pontos de coleta do monitoramento do lixiviado no corpo receptor.

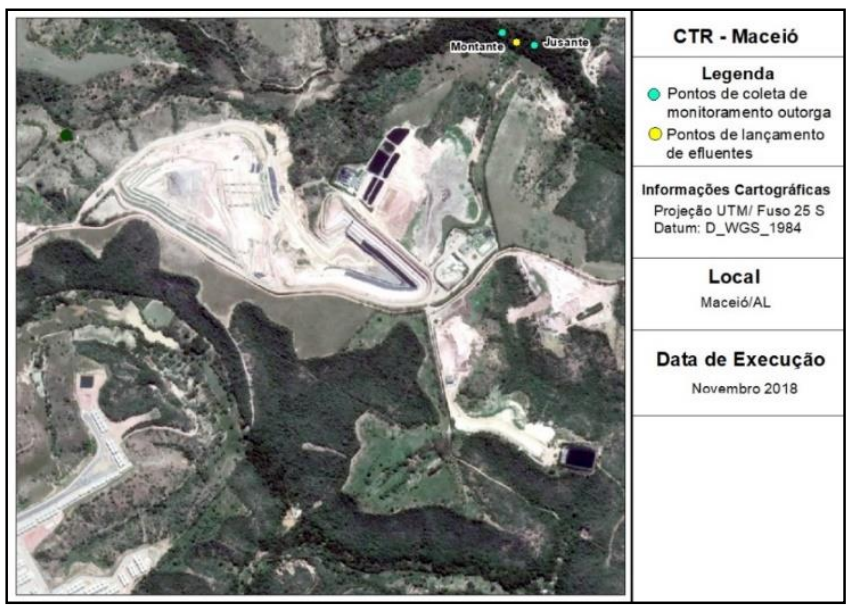

Fonte: Autores (2020).

\subsection{Avaliação da eficiência dos sistemas de tratamento}

O sistema de tratamento de lixiviados do aterro de Maceió sofreu modificações ao longo do tempo. Assim, buscou-se informações junto ao órgão acerca do histórico de funcionamento da estação de tratamento, e das tecnologias adotadas durante os anos de operação do aterro. Assim, optou-se por dividir a análise da eficiência em três períodos, 
porém não foi informado com precisão as mudanças ocorridas. O Figura 9 apresenta essa definição.

Figura 9 - Períodos das tecnologias de tratamento adotadas na ETE do aterro sanitário de Maceió.

\begin{tabular}{|c|c|}
\hline $\begin{array}{c}2010^{*}-2011 \\
\text { Período } 1\end{array}$ & $\begin{array}{c}2012-\text { set } / 2017 \\
\text { Período } 2\end{array}$ \\
\hline $\begin{array}{l}1 \text { - } 2 \text { Lagoas anaeróbias } \\
\text { em paralelo }\end{array}$ & $\begin{array}{l}1 \text {-2 Lagoas anaeróbias } \\
\text { em paralelo }\end{array}$ \\
\hline $\begin{array}{l}2 \text { - Processos físico- } \\
\text { quimimos (coagulação, } \\
\text { floculaçãoo e } \\
\text { decantação) }\end{array}$ & 2 - Lagoa pré aerada \\
\hline 3 - UASB & $\begin{array}{c}\text { 3-Processos físico- } \\
\text { quimicos }\end{array}$ \\
\hline $\begin{array}{l}4 \text { - Filtração (areia e } \\
\text { carvão ativado) }\end{array}$ & 4 -Lodos ativados \\
\hline $\begin{array}{l}5 \text { - Lagoa de polimento } \\
\text { final }\end{array}$ & $\begin{array}{c}5 \text { - Filtração (carvão } \\
\text { ativado) }\end{array}$ \\
\hline & $\begin{array}{l}6 \text { - Lagoa de polimento } \\
\text { final }\end{array}$ \\
\hline
\end{tabular}

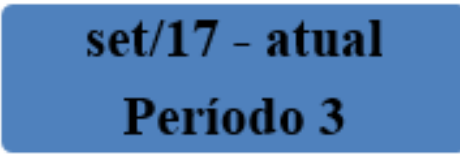

1 - Lagoa anaeróbia

2 - 2 Lagoas pré aeradas

3 - Lagoa aerada

4 - Processos físico químicos

5 - Filtração (zeólita)

6 - Adsorção (carvão ativado)

7 - Nanofiltração

8- Lagoa de polimento final

9 -Filtração (zeólita)

*Nos primeiros meses de 2010 a ETE só dispunha de uma lagoa anaeróbia e uma lagoa de acumulação. Fonte: Elaborado pelos Autores (2020).

A eficiência do sistema de tratamento empregado foi avaliada em função da remoção de DBO, DQO e nitrogênio amoniacal, e foi feita de forma global, levando-se em conta apenas dois pontos de amostragem, o efluente bruto (entrada no sistema) e o efluente tratado (saída do sistema).

A partir do mês de fevereiro de 2018, o monitoramento foi realizado em 4 (quatro) pontos de amostragem, nos seguintes locais: 
Research, Society and Development, v. 9, n. 7, e564974466, 2020

(CC BY 4.0) | ISSN 2525-3409 | DOI: http://dx.doi.org/10.33448/rsd-v9i7.4466

- $\quad$ Ponto 01 - Lixiviado Entrada (Figura 10a);

- $\quad$ Ponto 02 - Saída do processo Anaeróbio;

- $\quad$ Ponto 03 - Saída do processo Aeróbio (Figura 10b);

- $\quad$ Ponto 04 - Lixiviado Tratado (Figura 10c);

Figura 10 - Sistemas de monitoramento: (a) Coleta do lixiviado bruto; (b) Coleta do lixiviado após o processo aeróbio; e (c) Ponto de Coleta do lixiviado tratado.

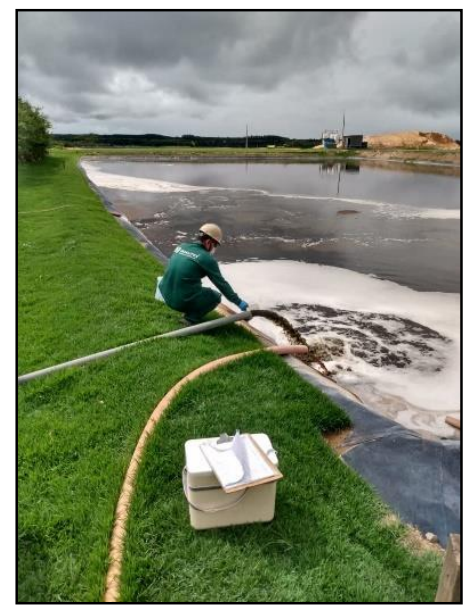

(a)

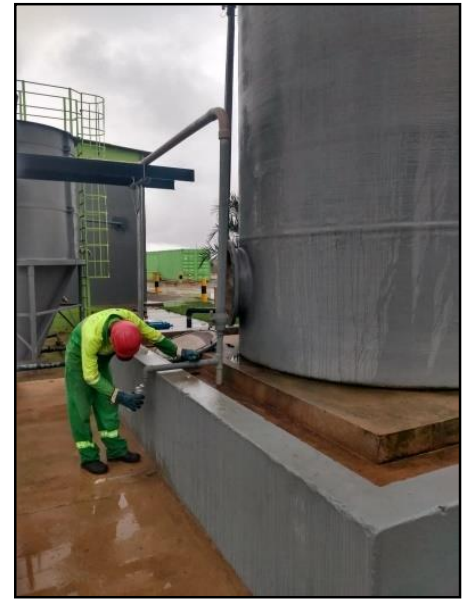

(b)

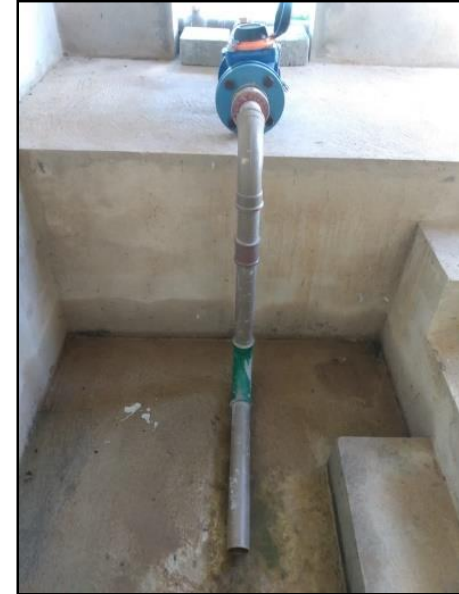

(c)

Fonte: Autores (2020).

Assim, para esses meses especificamente foram avaliadas as eficiências das remoções das concentrações dos parâmetros DBO, DQO e Nitrogênio Amoniacal após a saída de cada ponto de coleta, bem como contribuição da etapa biológica, após a saída dos processos anaeróbios e aeróbios e a contribuição da etapa físico-química, para a eficiência global do sistema. Os resultados foram comparados com os valores máximos permitidos (VMP) dispostos na Resolução CONAMA 430/2011 que dispõe sobre a classificação dos corpos de água e diretrizes ambientais para o seu enquadramento, bem como estabelece as condições e padrões de lançamento de efluentes, e dá outras providências. Especificamente, para o terceiro período, será comparado também com os valores estabelecidos pela outorga de lançamento concedida, em 2018, ao aterro sanitário para descarte em corpo hídrico Classe 2, conforme diretrizes da Resolução CONAMA 357/2005. A outorga em questão estabelece os limites máximos de DBO de $7 \mathrm{mg} / \mathrm{L}$ e nitrogênio amoniacal de $20 \mathrm{mg} / \mathrm{L}$. Ressalta-se que, assim como a Resolução CONAMA 430/2011, não há VMP para o parâmetro DQO. 


\section{Resultados e Discussões}

Na Tabela 1 são apresentas as médias das eficiências em função da estação utilizada no período analisados. Ressalta-se que não foi considerado o parâmetro nitrogênio amoniacal para o primeiro período da ETE, visto que não se possui os valores na saída da ETE para esse parâmetro.

Tabela 1 - Média das eficiências em função da estação utilizada.

\begin{tabular}{cccc}
\hline \multicolumn{4}{c}{ Médias eficiências } \\
\hline Período & DBO & DQO & $\begin{array}{c}\text { Nitrogênio } \\
\text { Amoniacal }\end{array}$ \\
\hline $\mathbf{1}$ & $57,68 \%$ & $56,24 \%$ & - \\
\hline $\mathbf{2}$ & $66,61 \%$ & $67,17 \%$ & $66,02 \%$ \\
\hline $\mathbf{3}$ & $98,79 \%$ & $95,45 \%$ & $93,42 \%$ \\
\hline
\end{tabular}

Fonte: Autores (2020).

Com exceção dos primeiros meses de 2010, nos três períodos os sistemas possuíam processos combinados com etapas biológicas e físico-químicas. Observa-se que no primeiro período os processos biológicos eram estritamente anaeróbios, através de lagoas anaeróbias e reator UASB, quanto aos processos físico-químicos, eram os mais comumente utilizados de coagulação, floculação, decantação e filtração. No segundo período houve a retirada do Reator UASB e inserção de processos biológicos aeróbios, mediante lagoa pré-aerada e lodos ativados. Jordão e Pessoa (2014) citam que no processo de filtração por membranas de nanofiltração há menor produção de lodo, se comparado ao sistema de lodos ativados, visto que na nanofiltração é realizada a recirculação, onde todo o processo de tratamento da fase sólida (lodo gerado) é minimizado.

No terceiro período há a retirada do sistema de lodos ativados e a inserção de lagoa aerada, além de nanofiltração e filtração com zeólitas, que configuraram em avanços no tratamento do lixiviado.

De fato, a partir da observação da Tabela 1, é possível perceber uma melhora significativa na eficiência de remoção dos parâmetros DBO, DQO e Nitrogênio Amoniacal com o passar dos períodos, ou seja, com as modificações ocorridas no sistema de tratamento. Esses fatos serão melhores discutidos nos itens posteriores. 


\section{- Remoção de DBO}

Na Figura 11 é apresentado os resultados relativos as eficiências para os três períodos da ETE para remoção de DBO.

Figura 11 - Eficiências de remoção de DBO para os três períodos.

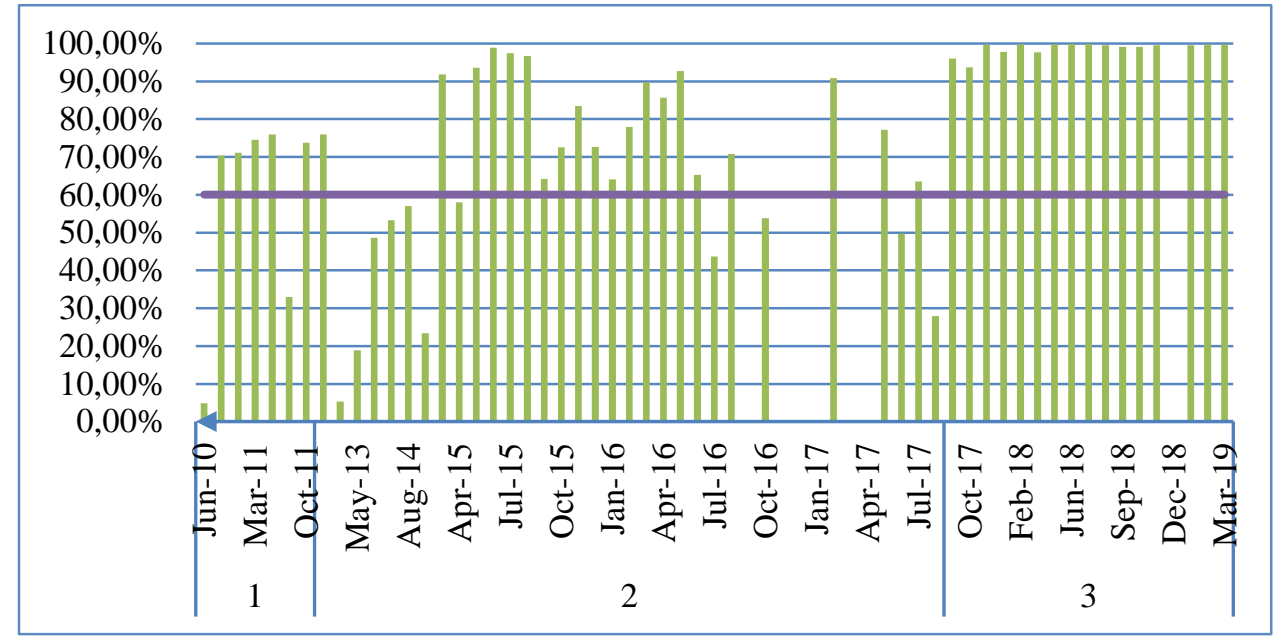

Fonte: Autores (2020).

Observando na Figura 11, para o período 1, na primeira análise realizada, em junho de 2010, observa-se apenas uma pequena remoção de DBO, de 4,93\%, o que pode ter ocorrido pelo fato da ETE ainda não ter sido implantada, havendo apenas uma lagoa anaeróbia e uma lagoa acumulação do lixiviado para posterior encaminhamento ao emissário submarino do município.

Nos meses posteriores, observa-se uma evolução na remoção da DBO, visto que foi acrescentado UASB e sistema físico-químico de coagulação, floculação e filtração com carvão ativado, obtendo eficiências em cerca de 70\%. Como as análises para esse período se limitam a dois pontos de amostragem, não é possível verificar a eficiência em cada etapa da estação.

Apesar da eficiência apresentar em 71,43\% das amostras, valores que atendem a resolução CONAMA 430/2011, que estabelece uma remoção mínima de 60\% para esse parâmetro, as cargas de entrada nesse período eram elevadas, visto que o aterro se encontrava no início de sua operação, assim, os valores de saída continuavam com cargas elevadas, com valor médio de $3.109 \mathrm{mg} / \mathrm{L}$, extremamente superior, por exemplo, ao valor tipicamente utilizado de esgoto, segundo Von Sperlling (1996), de 300 mg/L. Além disso, não se atenderia os padrões para descarte em corpo hídrico Classe II, assim, o lixiviado tratado era encaminhado ao emissário submarino do município. 
Em agosto de 2011 observa-se uma queda na eficiência, período em que foi verificado falhas no dimensionamento de alguns equipamentos, conforme relatado pela empresa operadora do aterro. Apesar da obtenção de resultados mais satisfatórios no mês subsequente, optou-se por modificações no sistema de tratamento.

De fato, a aplicação dos tratamentos biológicos em conjunto com os processos físicoquímicos para o primeiro período do aterro sanitário foi significativa para eficiência global na remoção da concentração de DBO do lixiviado.

Basicamente, a mudança do primeiro para o segundo período foi a retirada do UASB inserção de lagoa pré-aerada para mistura, e inserção de processo aeróbio, através de lodos ativados.

Nesse período já se observa diversas variações nas eficiências de tratamento obtidas, visto que se trata de um longo período de tempo, o que pode ter contribuído para essas oscilações. Observando o gráfico, percebe-se que o segundo período alcança eficiências mais elevadas, chegando a remoções de concentração de DBO superiores a 90\%.

O valor médio de DBO tratado apresentou redução significativa em relação ao primeiro período, com uma média de $812 \mathrm{mg} / \mathrm{L}$, porém ainda com valor consideravelmente elevado. 66,67\% das amostras apresentaram enquadramento na Resolução CONAMA 430 de 2011 para remoção de $60 \%$ de DBO, porém ainda sem atender aos padrões para descarte em corpo hídrico Classe II, assim, o lixiviado tratado era encaminhado ao emissário submarino do município, bem como para estações de tratamento localizadas nos estados da Bahia e Pernambuco.

Assim, a utilização de processos anaeróbios e aeróbios em conjunto com o sistema físico-químico, se mostrou positiva para o tratamento do lixiviado no aterro sanitário de Maceió, alcançando eficiências relevantes, apesar de possuir maiores oscilações devido ao longo período de tempo.

No terceiro período há a retirada do sistema de lodos ativados, e a inserção da lagoa aerada, filtração com zeólita e nanofiltração.

Analisando o gráfico demonstrado, é perceptível o avanço obtido com o sistema de tratamento do período 3, com eficiência média de 98,79\% para remoção de DBO. O valor médio da concentração de DBO após o tratamento foi de $17,75 \mathrm{mg} / \mathrm{L}$, o que provavelmente culminou para o pedido de outorga de lançamento em recurso hídrico, haja vista os resultados satisfatórios obtidos. $100 \%$ das amostras apresentaram enquadramento na Resolução CONAMA 430 de 2011 para remoção de 60\% de DBO e a partir de maio de 2018, as 
concentrações do lixiviado tratado atenderam aos padrões para descarte em corpo hídrico Classe II, de $7 \mathrm{mg} / \mathrm{L}$, estabelecido pela outorga.

De uma forma geral, na Figura 12 é apresentado os valores bruto e tratado para o parâmetro DBO durante os três períodos.

Figura 12 - Valores de DBO Bruto e Tratado.

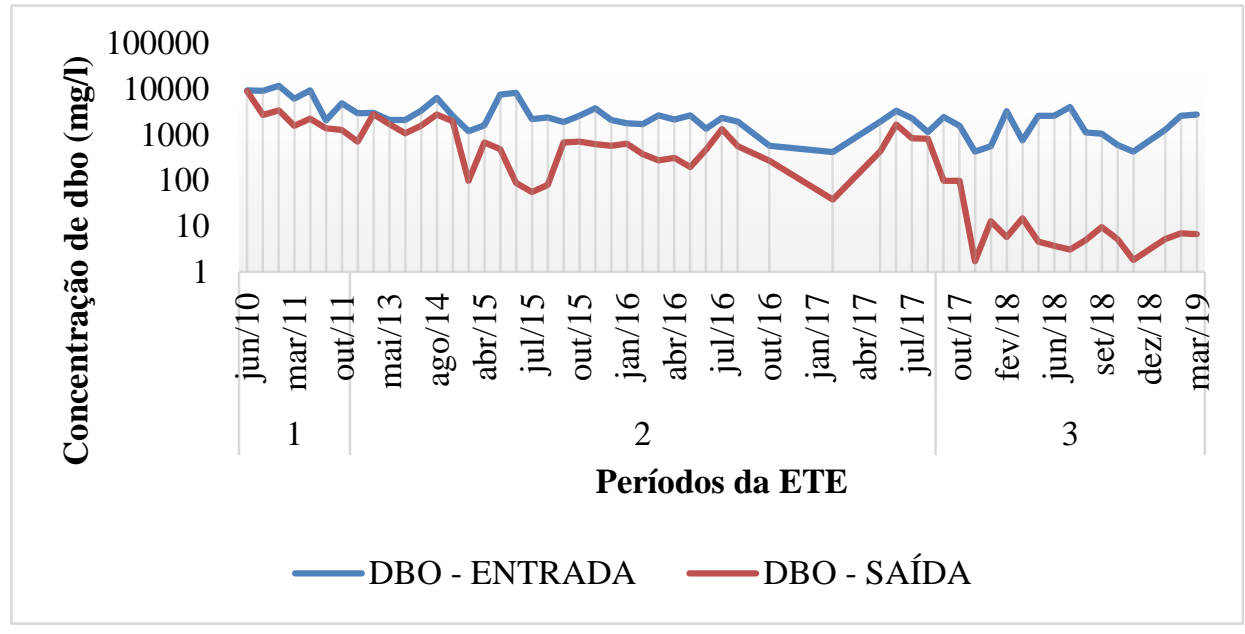

Fonte: Autores (2020).

Observando o gráfico é nítida a evolução na remoção da concentração de DBO com as modificações na ETE durante os três períodos, mediante as tecnologias adotadas, bem como adequações que foram realizadas durante esses períodos.

Com a análise da eficiência por etapa de tratamento, possibilitada a partir de fevereiro de 2018 e que será posteriormente discutida no presente estudo, será possível observar a influência da inserção desses novos sistemas que proporcionaram melhora significativa no tratamento do lixiviado.

\section{- Remoção de DQO}

Na Figura 13 são apresentados os resultados da remoção da concentração de DQO para o primeiro período da estação de tratamento. 
Figura 13 - Eficiência na remoção de DQO para os 3 períodos da ETE.

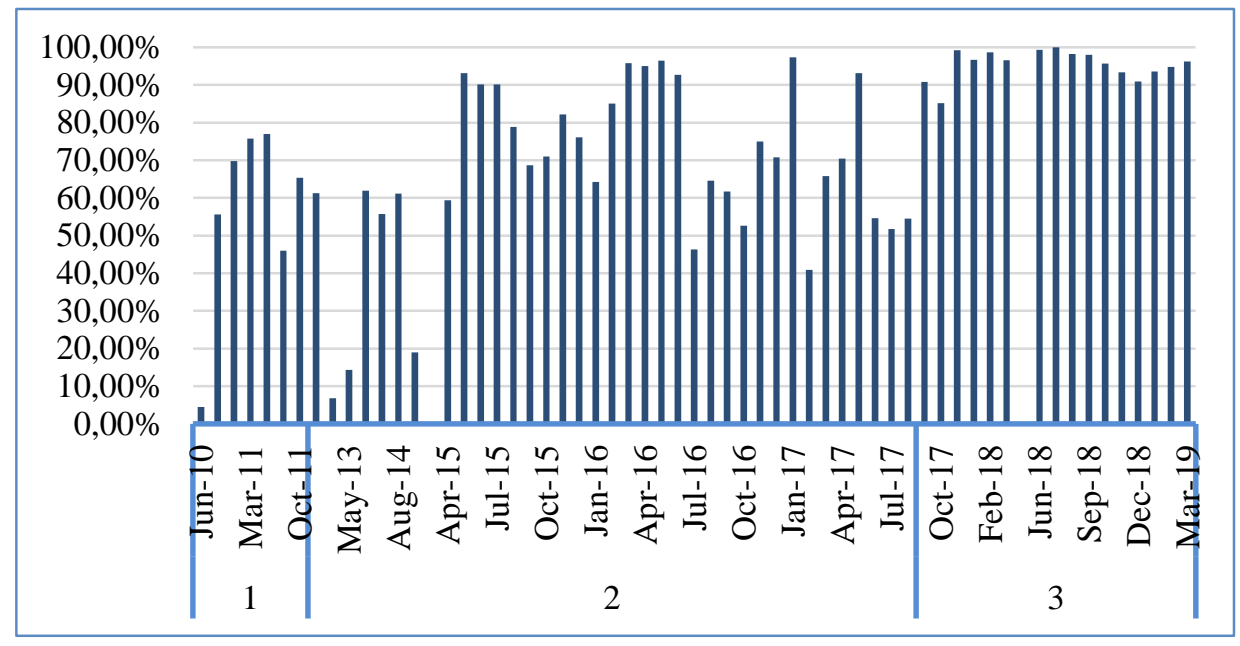

Fonte: Autores (2020)

Assim como para a remoção do DBO para o período 1, na primeira análise realizada, em junho de 2010, observa-se apenas uma pequena remoção de DQO, de 4,41\%, o que também pode ter ocorrido pelo fato da ETE ainda não ter sido implantada, havendo apenas para o período 1, na primeira análise realizada, em junho de 2010, observa-se apenas uma lagoa anaeróbia e uma lagoa acumulação do lixiviado para posterior encaminhamento ao emissário submarino do município. Como supracitado, apesar de lagoas anaeróbias serem eficientes na remoção de cargas orgânicas, há necessidade de certo tempo para a eficiência dos processos de degradação anaeróbia da matéria orgânica realizado principalmente pelas bactérias. Como o aterro era recém implantado, bem como deveria haver ainda pouca geração de lixiviado, pode não ter tido o tempo necessário para essa degradação.

Nos meses posteriores, também se observa uma evolução na remoção da DQO, visto que foi acrescentado UASB e sistema físico-químico de coagulação, floculação e filtração com carvão ativado, obtendo uma média de eficiência de 56,24\%. Como as análises para esse período se limitam a dois pontos de amostragem, não é possível verificar a eficiência em cada etapa da estação.

Semelhante ao ocorrido com a remoção de DBO, em agosto de 2011 observa-se uma queda na eficiência, período em que foi verificado falhas no dimensionamento de alguns equipamentos, conforme relatado pela empresa operadora do aterro. Apesar da obtenção de resultados mais satisfatórios no mês subsequente, optou-se por modificações no sistema de tratamento. 
Reiterando que, de fato, a aplicação dos tratamentos biológicos em conjunto com os processos físico-químicos para o primeiro período do aterro sanitário foi significativa para eficiência global na remoção da concentração de DQO do lixiviado.

Assim como para DBO, no segundo período também se observa maiores oscilações nas eficiências de tratamento obtidas, visto que se trata de um longo período de tempo. Observando o gráfico, percebe-se que o segundo período alcança eficiências mais elevadas, chegando a remoções de concentração de DQO que alcançam remoção de $95 \%$. As concentrações finais de DQO chegam a uma média $1.661 \mathrm{mg} / \mathrm{L}$, ainda com valor consideravelmente elevado. Maia et al. (2015), em sistema composto de lagoas anaeróbias e de lodos ativados obtiveram uma eficiência de $68 \%$ para DQO e um valor remanescente também elevado de $1.086 \mathrm{mg} / \mathrm{L}$.

De toda forma, para o período 2, a utilização de processos anaeróbios e aeróbios em conjunto com o sistema físico-químico, se mostrou positiva para o tratamento do lixiviado no aterro sanitário de Maceió, alcançando eficiências relevantes, apesar de possuir maiores oscilações devido ao longo período de tempo.

No terceiro período há a retirada do sistema de lodos ativados, e a inserção de lagoa aerada, filtração com zeólita e nanofiltração.

Analisando o gráfico demonstrado na Figura 13, no período 3, é verificado o avanço obtido com o sistema de tratamento correspondente ao período 3, com eficiência média de 95,45\% para remoção de DQO, com valor médio de concentração após tratamento de 208,49 $\mathrm{mg} / \mathrm{L}$.

De uma forma geral, na Figura 14 são apresentados os valores bruto e tratado para o parâmetro DQO durante os três períodos. 
Figura 14 - Valores de DQO bruto e tratado.

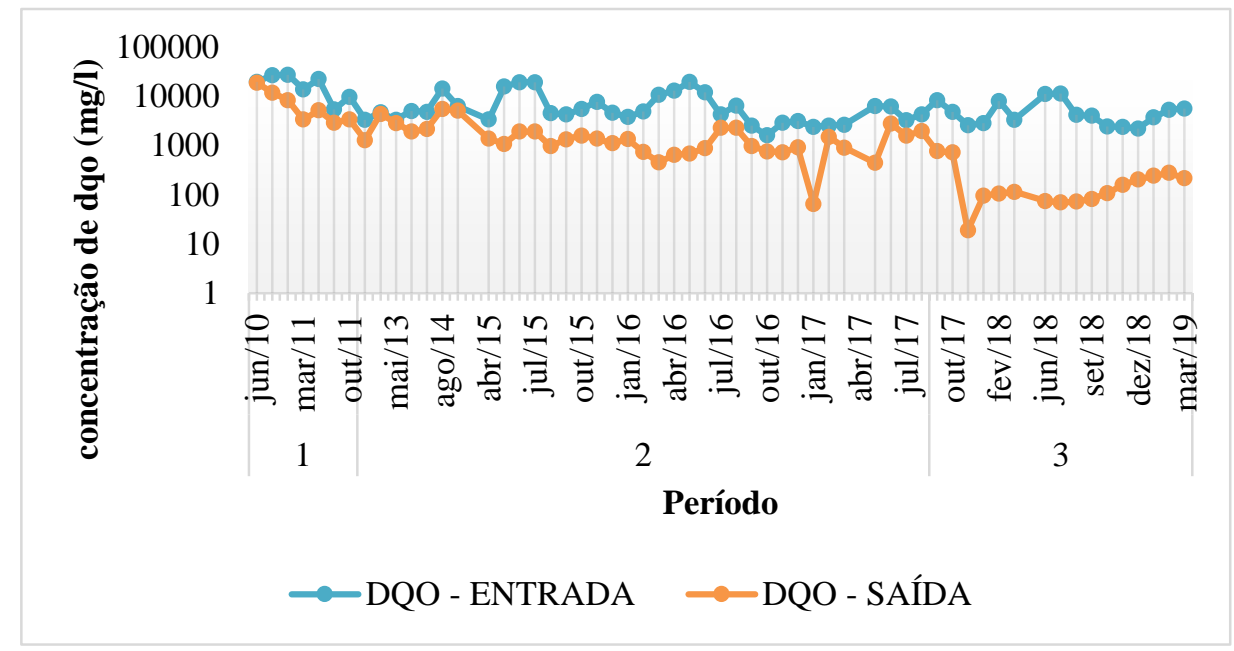

Fonte: Autores (2020).

Observando o gráfico é nítida a evolução na remoção da concentração de DQO com as modificações na ETE durante os três períodos, mediante as tecnologias adotadas, bem como adequações que foram realizadas durante esses períodos.

Com a análise da eficiência por etapa de tratamento, possibilitada a partir de fevereiro de 2018 e que será posteriormente discutida no presente estudo, será possível observar a influência da inserção desses novos sistemas que proporcionaram melhora significativa para o período 3.

Como era previsto, a redução da concentração de DQO durante os períodos se comportou de maneira semelhante com a redução da concentração de DBO, nos diferentes períodos analisados.

\section{- Remoção de Nitrogênio Amoniacal}

No tratamento de lixiviados de aterros sanitários, a remoção das elevadas concentrações de nitrogênio amoniacal são uma das maiores problemáticas enfrentadas (Maia et al., 2015; Lins, 2019). Como não há valores de concentração de nitrogênio amoniacal tratado para o primeiro período, o Figura 15 apresenta as eficiências de remoção desse parâmetro para o segundo período. 
Research, Society and Development, v. 9, n. 7, e564974466, 2020

(CC BY 4.0) | ISSN 2525-3409 | DOI: http://dx.doi.org/10.33448/rsd-v9i7.4466

Figura 15 - Eficiência de remoção da concentração de nitrogênio amoniacal para o segundo período.

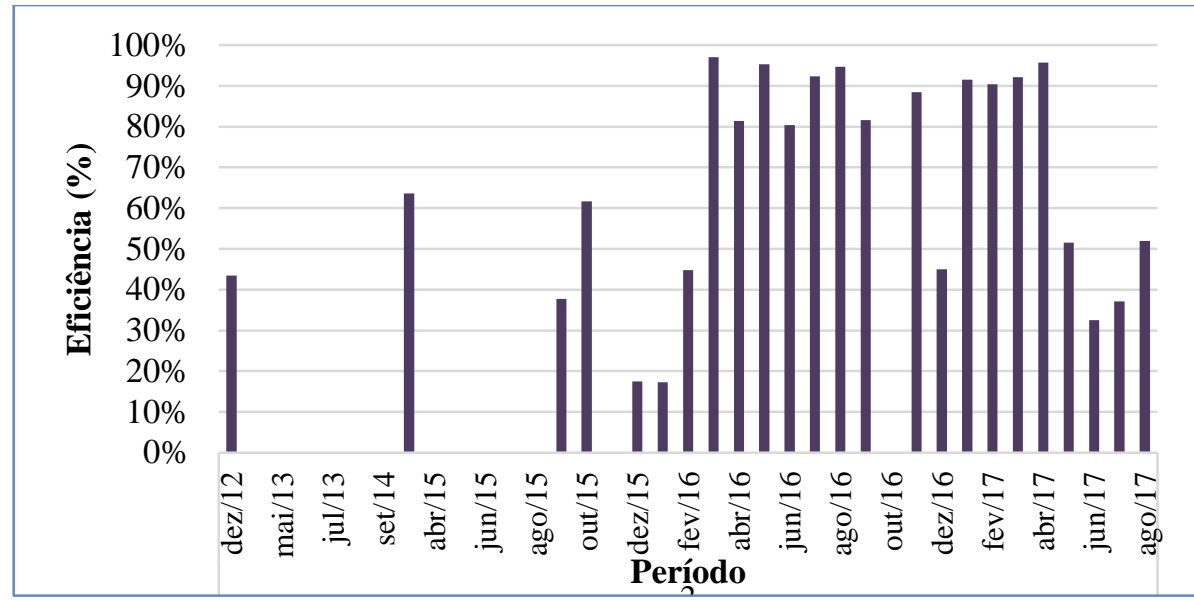

Fonte: Autores (2020).

Não se observa muitas oscilações nas eficiências obtidas para remoção da concentração de NA, mas ressalta-se que há um número consideravelmente inferior de análises realizadas. A média de eficiência para o período 2 é de 66,02\%. Apesar de eficiências que chegam a valores superiores a 90\%, observando o gráfico, percebe-se que há redução das eficiências a partir de meados de 2017, indicando a necessidade de melhoria no sistema. Além disso, não se obteve atendimento de concentração final de $20 \mathrm{mg} / \mathrm{L}$ (Figura 16), estabelecido pela Resolução CONAMA 430 de 2011, sendo a média de concentração de NA no lixiviado tratado de $442,18 \mathrm{mg} / \mathrm{L}$.

Figura 16 - Concentrações finais de NA no período 2.

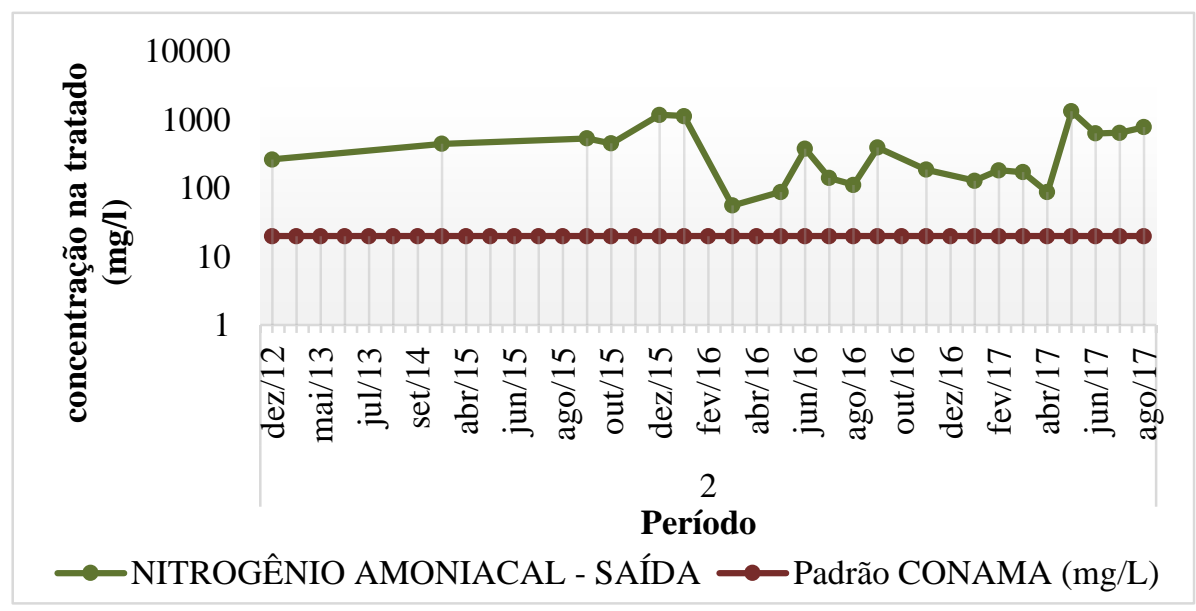

Fonte: Autores (2020). 
Maia et al. (2015) no sistema composto de lagoas anaeróbia se de lodos ativados obteve uma eficiência média de $83 \%$ na remoção de NA, porém com valor final que também não atendia aos padrões estabelecidos pela legislação, citando a necessidade de tratamentos adicionais

As concentrações elevadas de nitrogênio amoniacal podem ter contribuído para o desempenho do sistema de lodos ativados, Li e Zhao (1999, apud Albuquerque, 2012), verificaram que quando as concentrações de nitrogênio amoniacal aumentaram para $800 \mathrm{mg} / \mathrm{L}$, a eficiência de remoção desse parâmetro no sistema de lodos ativados decaiu.

De toda forma, é importante ressaltar que como não há resultados após cada etapa de tratamento, não é possível relatar a eficiência de cada processo. De fato, é verificada a necessidade de tratamentos adicionais para remoção de nitrogênio amoniacal, especialmente para atendimento ao estabelecido pela Resolução CONAMA 430 de 2011, o que deve ter proporcionado a mudança no sistema de tratamento do aterro sanitário de Maceió, culminando com a adição dos sistemas de filtração com zeólitas e nanofiltração.

Na Figura 17 são apresentados os resultados relativos as eficiências de remoção das concentrações de Nitrogênio Amoniacal para o terceiro período.

Figura 17 - Eficiência de remoção da concentração de NA no período 3.

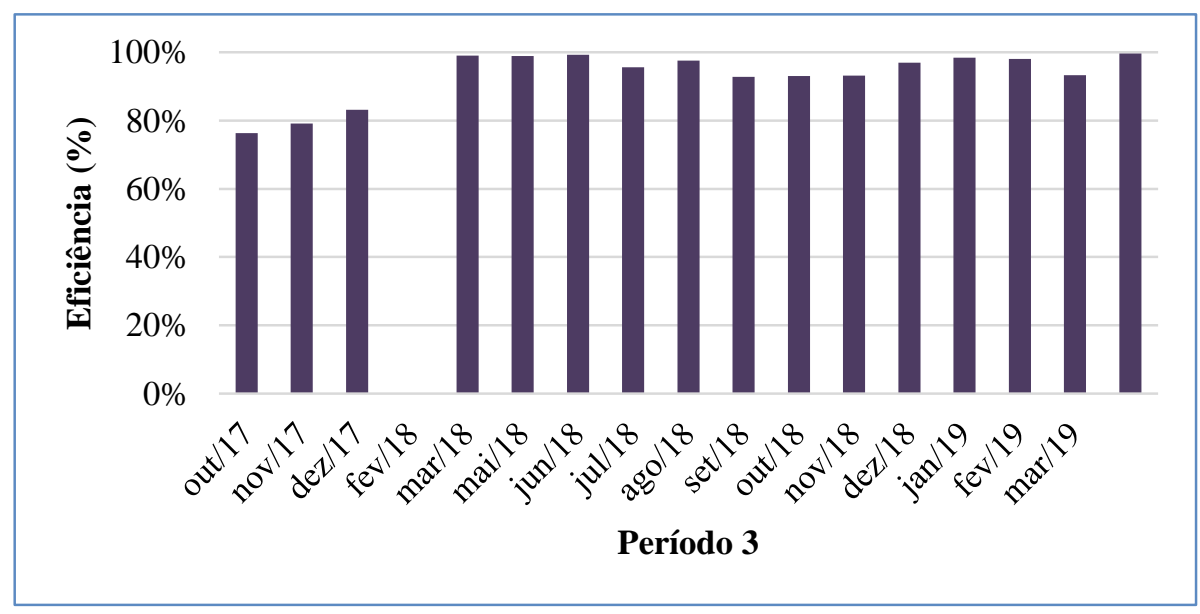

Fonte: Autores (2020).

Analisando o demonstrado a Figura 17, é verificado o avanço obtido com o sistema de tratamento correspondente ao período 3, com eficiência média de 93,42\% para remoção de NA, com valor médio de concentração após tratamento de 106,09 mg/L. Na última análise realizada, no mês de março de 2019, a concentração de NA no lixiviado tratado obteve valor 
(CC BY 4.0) | ISSN 2525-3409 | DOI: http://dx.doi.org/10.33448/rsd-v9i7.4466

de 7,60 mg/L, obtendo valor permitido pela Resolução CONAMA 430 de 2011, bem como pela outorga de lançamento em corpo hídrico.

Com a análise da eficiência por etapa de tratamento, possibilitada a partir de fevereiro de 2018 e que será posteriormente discutida no presente estudo, será possível observar a influência da inserção desses novos sistemas que proporcionaram melhora significativa para o período 3.

\section{- Avaliação da eficiência por etapa de tratamento}

Conforme já citado no presente estudo, a partir do mês de fevereiro de 2018, as coletas para realização das análises no lixiviado gerados no aterro sanitário de Maceió foram realizados em 4 pontos de amostragem. Como já discutido anteriormente, foi constatada a melhoria nas eficiências obtidas na remoção dos parâmetros DBO, DQO e Nitrogênio Amoniacal após a implantação da ETE atualmente utilizada. Assim, os tópicos posteriores visam discutir acerca dos resultados obtidos após algumas desse sistema, onde são realizadas as coletas para análise, bem como sua contribuição na eficiência global do tratamento.

\section{- Remoção de DBO}

É apresentado na Tabela 2 os resultados das eficiências e valores de concentrações de DBO obtidos após as etapas de tratamento onde são realizadas as coletas para análise do lixiviado, sendo estas: Eficiência 1: Após a lagoa anaeróbia; Eficiência 2: após o processo aeróbio; e Eficiência 3: após passagem pelos processos físico-químicos e nanofiltração, já relatados na metodologia do presente estudo. A eficiência global é correspondente a eficiência de todo o sistema de tratamento atualmente utilizado, compreendendo todas as etapas. Complementarmente, na Figura 18 é demonstrado esses valores de concentrações.

Analisando a Tabela 2, observa-se um pequeno aumento na concentração de DBO após a passagem pelo processo aeróbio (out/18 e mar/19), tal fato pode ter sido atribuído por algum carreamento de sólidos na passagem de uma etapa para a outra. É possível perceber que os valores de DBO removidos após o processo biológico (anaeróbio e aeróbios), na maioria das amostras, apresenta eficiências elevadas, com cargas finais com valor médio de 340,88 mg/L, que é reduzido expressivamente após os processos físico-químicos, alcançando valor médio de $6,06 \mathrm{mg} / \mathrm{L}$. 
Research, Society and Development, v. 9, n. 7, e564974466, 2020

(CC BY 4.0) | ISSN 2525-3409 | DOI: http://dx.doi.org/10.33448/rsd-v9i7.4466

Tabela 2 - Eficiências e valores de concentrações de DBO obtidos após as etapas de tratamento.

\begin{tabular}{|c|c|c|c|c|c|c|c|c|}
\hline Mês/Ano & $\begin{array}{c}\text { DBO } \\
\text { bruto } \\
\text { (mg/L) }\end{array}$ & $\begin{array}{c}\text { DBO após } \\
\text { anaeróbio } \\
(\mathbf{m g} / \mathbf{L})\end{array}$ & $\begin{array}{c}\text { Eficiência } \\
1(\%)\end{array}$ & $\begin{array}{c}\text { DBO } \\
\text { após } \\
\text { aeróbio } \\
(\mathbf{m g} / \mathrm{L})\end{array}$ & $\begin{array}{c}\text { Eficiência } \\
2(\%)\end{array}$ & $\begin{array}{c}\text { DBO } \\
\text { final } \\
(\mathbf{m g} / \mathbf{L})\end{array}$ & $\begin{array}{c}\text { Eficiência3 } \\
(\%)\end{array}$ & $\begin{array}{c}\text { Eficiência } \\
\text { Global } \\
(\%)\end{array}$ \\
\hline fev/18 & 3325 & 789 & 76,27 & 99 & 87,45 & 5,80 & 94,14 & 99,83 \\
\hline mar/18 & 754 & 640 & 15,12 & 121 & 81,09 & 14,90 & 87,69 & 97,67 \\
\hline mai/18 & 2637 & 847 & 67,89 & 363 & 57,07 & 4,61 & 98,73 & 99,83 \\
\hline jun/18 & 2602 & 1128 & 56,66 & 258 & 77,07 & 3,77 & 98,54 & 99,86 \\
\hline jul/18 & 4044 & 1772 & 56,19 & 363 & 79,48 & 3,07 & 99,16 & 99,92 \\
\hline ago/18 & 1135 & 814 & 28,27 & 814 & 0,06 & 5,00 & 99,39 & 99,56 \\
\hline set/18 & 1059 & 762 & 28,02 & 458 & 39,92 & 9,61 & 97,90 & 99,09 \\
\hline out/18 & 605 & 307 & 49,33 & 311 & $-1,51$ & 5,25 & 98,32 & 99,13 \\
\hline nov/18 & 426 & 331 & 22,23 & 294 & 11,20 & 1,84 & 99,38 & 99,57 \\
\hline jan/19 & 1284 & 342 & 73,38 & 328 & 4,09 & 5,24 & 98,40 & 99,59 \\
\hline fev/19 & 2618 & 600 & 77,05 & 329 & 45,10 & 6,98 & 97,88 & 99,73 \\
\hline $\mathrm{mar} / 19$ & 2810 & 336 & 88,03 & 348 & $-3,47$ & 6,70 & 98,08 & 99,76 \\
\hline
\end{tabular}

Fonte: Autores (2020).

Figura 18 - Concentrações de DBO após as etapas de tratamento do lixiviado.

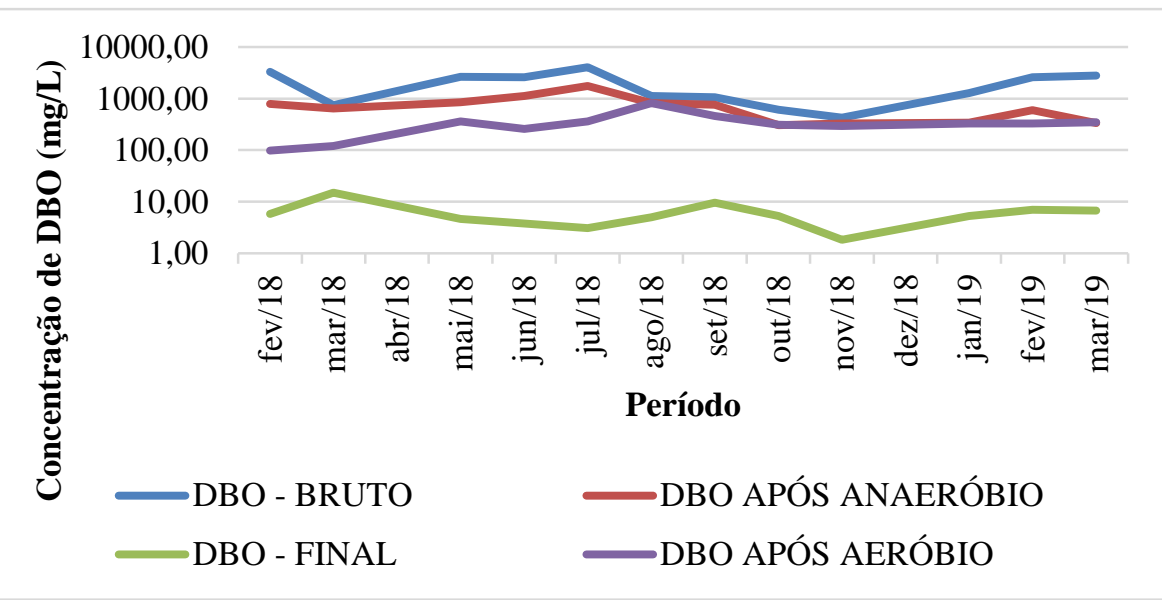

Fonte: Autores (2020). 
Observa-se, ainda, grandes oscilações nas eficiências desses sistemas anaeróbios e aeróbios, o que pode indicar que outros fatores possuem influência sobre eles, tais como temperatura, $\mathrm{pH}, \mathrm{TDH}$, entre outros e que devem ser melhor analisados.

Nesse sentido, na Figura 19 é apresentada a contribuição da etapa biológica do sistema e da etapa físico-química na eficiência global do sistema para remoção da DBO.

Figura 19 - Contribuição do processo biológico e físico químico na eficiência global do sistema para remoção de DBO.

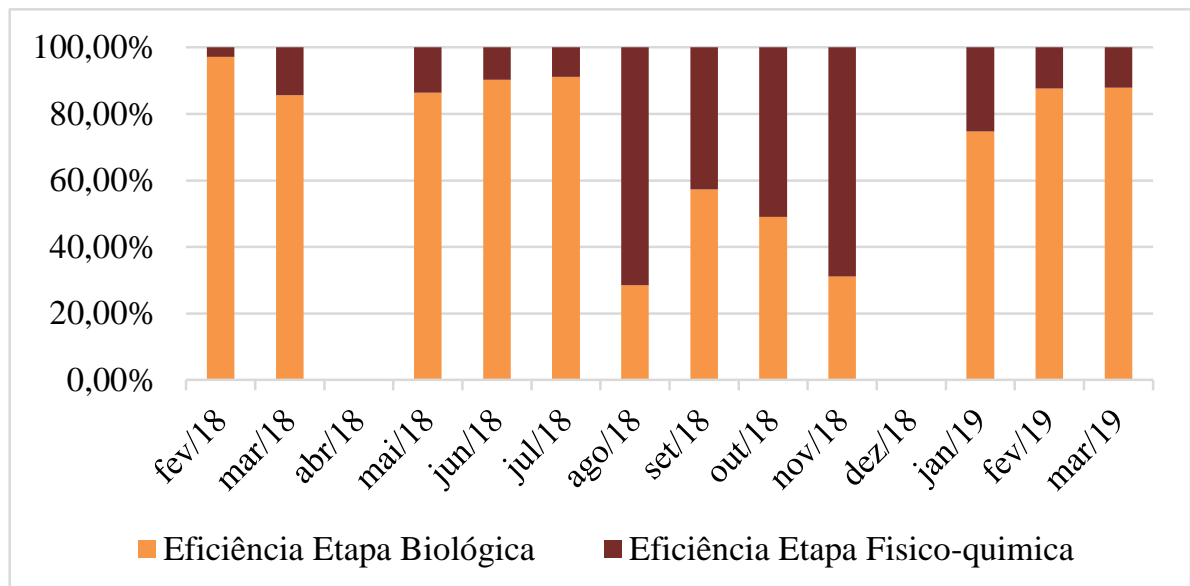

Fonte: Autores (2020).

Os processos biológicos constituídos de lagoa anaeróbia, lagoa pré-aerada e lagoa aerada da ETE contribuíram em média em $72,21 \%$ para a eficiência global do sistema, os processos físico-químicos de coagulação, floculação, decantação, filtração (carvão ativado e zeólita) e nanofiltração em média de 27,79\%. Analisando a Figura 19, a eficiência da contribuição dos processos biológicos é inferior em concentrações menores, possivelmente pela menor contribuição de carga orgânica presente no lixiviado.

Os processos biológicos são eficientes na remoção das cargas orgânicas, fato esse demonstrado pela diminuição da DBO após esses processos. Com a utilização da etapa físico-química, os valores foram reduzidos a concentrações de DBO inferiores a $15 \mathrm{mg} / \mathrm{L}$. De forma global, o sistema utilizado apresentou eficiência média de 99,46\%, indicando que todos esses processos combinados foram extremamente eficientes para remoção de DBO presente no lixiviado. 


\section{- Remoção de DQO}

Na Tabela 3 são apresentados os resultados das eficiências e valores de concentrações de DQO obtidos após as etapas de tratamento onde são realizadas as coletas para análise do lixiviado, sendo estas: Entrada do sistema, após a lagoa anaeróbia, após o processo aeróbio e após passagem pelos processos físico-químicos já relatados na metodologia do presente estudo. Complementarmente, na Figura 20 são apresentados esses valores de concentrações.

Tabela 3 - Eficiências e valores de concentrações de DQO obtidos após as etapas de tratamento.

\begin{tabular}{|c|c|c|c|c|c|c|c|c|}
\hline $\begin{array}{l}\text { Mês/ } \\
\text { Ano }\end{array}$ & $\begin{array}{l}\text { DQO - } \\
\text { bruto } \\
(\mathrm{mg} / \mathrm{L})\end{array}$ & $\begin{array}{c}\text { DQO após } \\
\text { anaeróbio } \\
\text { (mg/L) }\end{array}$ & $\begin{array}{l}\text { Eficiênc } \\
\text { ia } 1(\%)\end{array}$ & $\begin{array}{c}\text { DQO } \\
\text { após } \\
\text { aeróbio } \\
(\mathbf{m g} / \mathrm{L})\end{array}$ & $\begin{array}{l}\text { Eficiênc } \\
\text { ia } 2(\%)\end{array}$ & $\begin{array}{c}\text { DQO - } \\
\text { final } \\
(\mathrm{mg} / \mathrm{L})\end{array}$ & $\begin{array}{c}\text { Eficiênci } \\
\quad \mathbf{a} \\
3(\%)\end{array}$ & $\begin{array}{c}\text { Eficiênc } \\
\text { ia global } \\
(\%)\end{array}$ \\
\hline fev/18 & 8130 & 2640 & 67,53 & 1200 & 54,55 & 105,00 & 91,25 & 98,71 \\
\hline mar/18 & 3360 & 3490 & $-3,87$ & 1680 & 51,86 & 115,00 & 93,15 & 96,58 \\
\hline mai/18 & 4117 & 3041 & 26,11 & 1114 & 63,35 & 70,67 & 93,66 & 90,41 \\
\hline jun/18 & 11177 & 3442 & 69,20 & 1178 & 65,75 & 74,24 & 93,70 & 99,34 \\
\hline jul/18 & 11470 & 2755 & 75,98 & 1092 & 60,33 & 70,00 & 93,59 & 99,39 \\
\hline ago/18 & 4188 & 2755 & 34,23 & 1092 & 60,33 & 72,71 & 93,35 & 98,26 \\
\hline set/18 & 4045 & 2510 & 37,95 & 1230 & 51,00 & 82,36 & 93,30 & 97,96 \\
\hline out/18 & 2464 & 1521 & 38,24 & 1179 & 22,50 & 106,64 & 90,96 & 95,67 \\
\hline nov/18 & 2385 & 2059 & 13,67 & 1499 & 27,21 & 157,88 & 89,47 & 93,38 \\
\hline $\operatorname{dez} / 18$ & 2236 & 1939 & 13,27 & 1711 & 11,76 & 203,61 & 88,10 & 90,89 \\
\hline jan/19 & 3757 & 1808 & 51,88 & 1595 & 11,76 & 242,27 & 84,82 & 93,55 \\
\hline fev/19 & 5367 & 1850 & 65,53 & 1746 & 5,61 & 279,03 & 84,02 & 94,80 \\
\hline mar/19 & 5708 & 2309 & 59,54 & 1654 & 28,35 & 215,53 & 86,97 & 96,22 \\
\hline
\end{tabular}


Research, Society and Development, v. 9, n. 7, e564974466, 2020

(CC BY 4.0) | ISSN 2525-3409 | DOI: http://dx.doi.org/10.33448/rsd-v9i7.4466

Figura 20 - Concentrações de DQO após as etapas de tratamento do lixiviado.

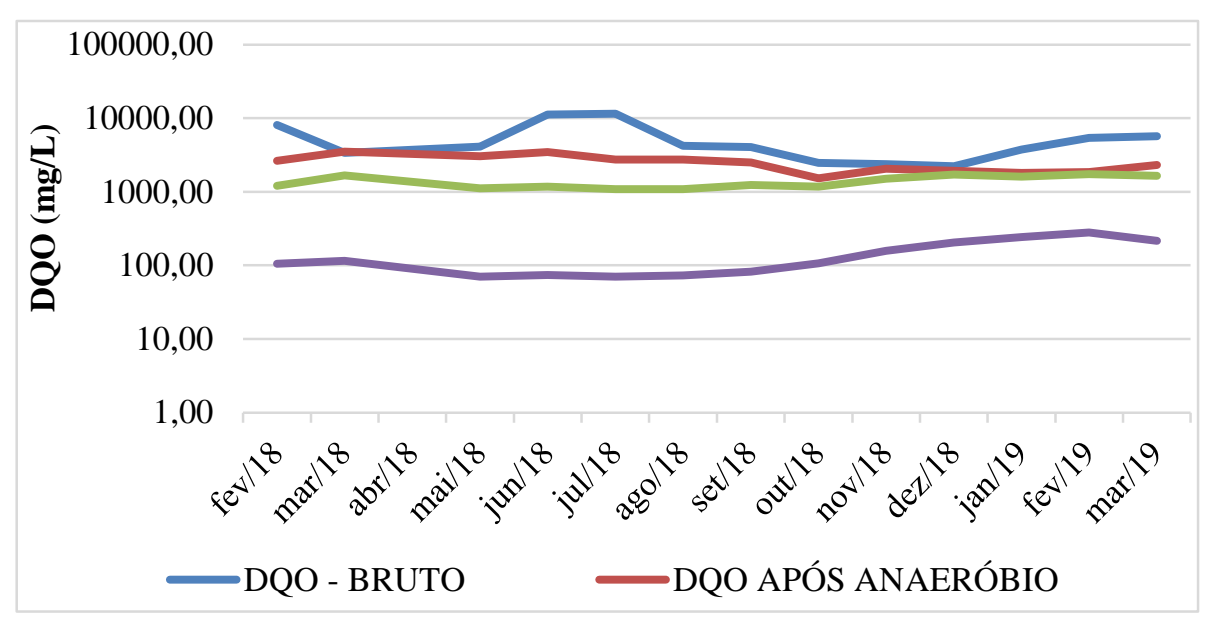

Fonte: Autores (2020).

Analisando a Tabela 3, também se observa um pequeno aumento na concentração de DQO após a passagem pelo processo anaeróbio (mar/18), tal fato pode ter sido atribuído por algum carreamento de sólidos na passagem de uma etapa para a outra.

As eficiências na remoção de DQO após o processo biológico anaeróbio apresentou eficiência inferior em relação a remoção de DBO.

A DQO residual após essas etapas é elevada, com valores superiores a $1000 \mathrm{mg} / \mathrm{L}$, que pode ser justificada pelo fato de como nesse período o aterro já se encontra com relações DBO/DQO menores, conforme já demonstrado, deve haver quantidade de matéria orgânica resistente a oxidação biológica, dificultando a remoção da DQO residual. Assim como para remoção de DBO, observa-se, ainda, grandes oscilações nas eficiências desses sistemas anaeróbios e aeróbios, o que pode indicar que outros fatores possuem influência sobre eles, tais como temperatura, $\mathrm{pH}, \mathrm{TDH}$, entre outros e que devem ser melhor analisados. Abbas et al. (2009) relata, por exemplo, que a dependência da temperatura nos tratamentos por lagoas pode ser uma limitação significativa porque pode afetar a atividade microbiana.

Especialmente o processo aeróbio apresenta um papel importante no sistema, visto que, em ambiente aeróbio, as bactérias nitrificantes são capazes de converter nitrogênio amoniacal em nitrito e nitrato, através da oxidação biológica da amônia. A média de remoção de DQO nesse processo foi de 39,57\%. Moravia et al. (2009) observaram, para sistema de lagoas aeradas, remoções de DQO na ordem de $34 \%$.

As etapas físico-químicas utilizadas alcançaram eficiências na ordem de $90 \%$, diminuindo expressivamente a DQO residual. 
Sob esse contexto, na Figura 21 é apresentada a contribuição da etapa biológica do sistema e da etapa físico-química na eficiência global do sistema para remoção da DQO.

Figura 21 - Contribuição do processo biológico e físico químico na eficiência global do sistema para remoção de DQO.

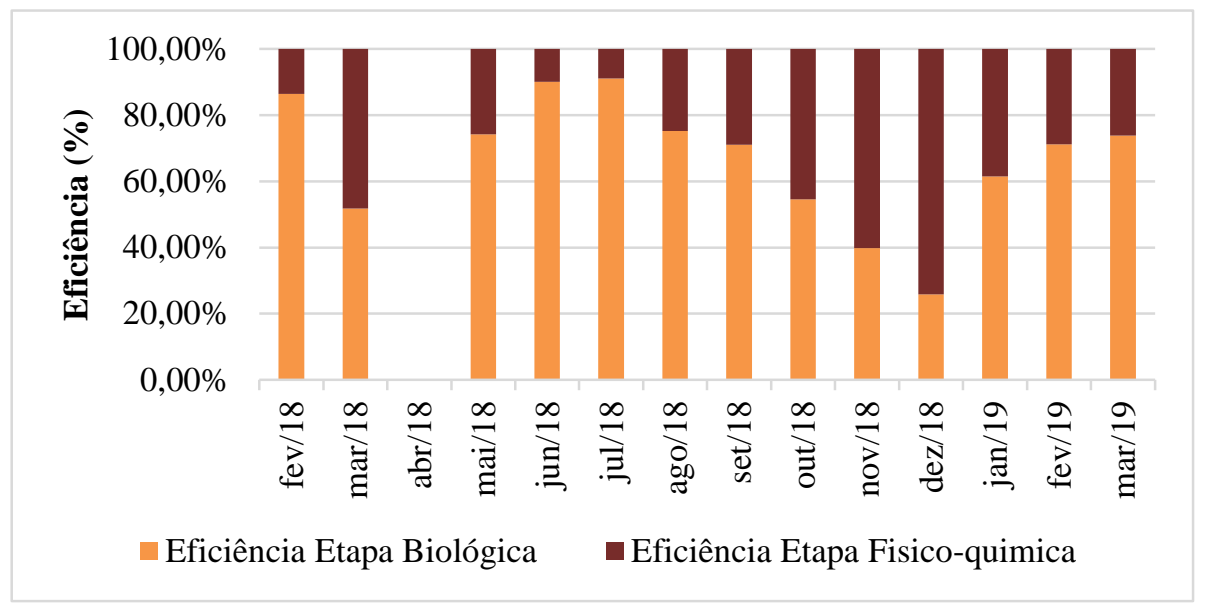

Fonte: Autores (2020).

Analisando a Figura 21, os processos biológicos constituídos de lagoa anaeróbia, lagoa pré-aerada e lagoa aerada da ETE contribuíram em média em 66,63\% para a eficiência global do sistema, os processos físico-químicos de coagulação, floculação, decantação, filtração (carvão ativado e zeólita) e nanofiltração em média de 33,37\%.

Reitera-se que a eficiência da contribuição dos processos biológicos se limita para a remoção de DQO quando da diminuição da relação DBO/DQO, que apresentou média de 0,2 nesse período. Souto (2009) cita que parte da DQO é justamente composta pelos ácidos húmicos e fúlvicos, que não são facilmente biodegradáveis, especialmente em aterros com mais idade, que tem características recalcitrantes.

Com a etapa físico-química, as concentrações de DQO diminuíram de forma expressiva, alcançando uma concentração média de DQO final de 138,07 mg/L. O processo de nanofiltração deve ter contribuído de forma significativa para redução na concentração de DQO. A eficiência após esses processos obteve média de 90\%. Silva (2017) obteve eficiência de 96\% na remoção de DQO utilizando nanofiltração como etapa de pós-tratamento. Assim como a utilização de zeólitas e carvão ativado na filtração, como já citado, Kirmizakis et. Al (2014) utilizaram o processo de adsorção utilizando carvão ativado granular no póstratamento do lixiviado gerado em um aterro sanitário que também possuia baixa relação DBO/DQO, alcançando eficiências entre 45 a 76\%. Kargi e Pamukoglu (2004) também 
utilizaram o carvão ativado e zeólita como adsorventes obtendo eficiências de $87 \%$ e $77 \%$, respectivamente.

Conclui-se que os processos biológicos são eficientes para a remoção de matéria orgânica, porém quando da diminuição da relação da DBO/DQO, como é o caso do aterro sanitário de Maceió nesse período, fica clara a necessidade de tratamentos físico-químicos complementares para remoção da DBO remanescente, visto que, conforme citado por Abbas et al. (2009) grande parte do lixiviado tratado biologicamente é composto por moléculas orgânicas recalcitrantes, que não são facilmente removidas durante o tratamento biológico.

Castilhos Jr. et al. (2009) cita que de fato os sistemas de lagoas apresentam dificuldades na remoção desses compostos refratários, que ocasionam elevadas cargas de DQO. Nesse caso, os processos de nanofiltração e adsorção com carvão ativado e zeólitas tiveram papel relevante para a redução na concentração de DQO.

De forma global, o sistema utilizado apresentou eficiência média de 95,78\%, indicando que todos esses processos combinados foram vantajosos para remoção de DQO presente no lixiviado.

\section{- Remoção de Nitrogênio Amoniacal}

$\mathrm{Na}$ Tabela 4 são apresentadas as eficiências e valores de concentrações de NA obtidos após as etapas de tratamento onde são realizadas as coletas para análise do lixiviado, sendo estas: Entrada do sistema, após a lagoa anaeróbia, após o processo aeróbio e após passagem pelos processos físico-químicos já relatados na metodologia do presente estudo. Complementarmente, na Figura 22 são apresentados esses valores de concentrações. 
Research, Society and Development, v. 9, n. 7, e564974466, 2020

(CC BY 4.0) | ISSN 2525-3409 | DOI: http://dx.doi.org/10.33448/rsd-v9i7.4466

Tabela 4 - Eficiências e valores de concentrações de DQO obtidos após as etapas de tratamento.

\begin{tabular}{|c|c|c|c|c|c|c|c|c|}
\hline $\begin{array}{l}\text { Mês/ } \\
\text { Ano }\end{array}$ & $\begin{array}{c}\text { NA } \\
\text { bruto } \\
\text { (mg/L) }\end{array}$ & $\begin{array}{c}\text { NA após } \\
\text { anaeróbio } \\
(\mathrm{mg} / \mathrm{L})\end{array}$ & $\begin{array}{c}\text { Eficiênci } \\
\text { a } 1(\%)\end{array}$ & $\begin{array}{c}\text { NA após } \\
\text { aeróbio } \\
(\mathrm{mg} / \mathrm{L})\end{array}$ & $\begin{array}{c}\text { Eficiênci } \\
\text { a } 2(\%)\end{array}$ & $\begin{array}{c}\text { NA } \\
\text { final } \\
(\mathrm{mg} / \mathrm{L})\end{array}$ & $\begin{array}{c}\text { Eficiênci } \\
\text { a3 (\%) }\end{array}$ & $\begin{array}{c}\text { Eficiênci } \\
\text { a global } \\
(\%)\end{array}$ \\
\hline fev/18 & 2400 & 1640 & 31,67 & 579 & 64,70 & 22,50 & 96,11 & 99,06 \\
\hline mar/18 & 2350 & 1520 & 35,32 & 328 & 78,42 & 23,90 & 92,71 & 98,98 \\
\hline mai/18 & 1910 & 1380 & 27,75 & 267 & 80,65 & 14,60 & 94,53 & 99,24 \\
\hline jun/18 & 785 & 817 & $-4,08$ & 379 & 53,61 & 53,30 & 85,94 & 93,21 \\
\hline jul/18 & 1560 & 1330 & 14,74 & 738 & 44,51 & 37,00 & 94,99 & 97,63 \\
\hline ago/18 & 1030 & 1150 & $-11,65$ & 472 & 58,96 & 74,30 & 84,26 & 92,79 \\
\hline set/18 & 2140 & 1160 & 45,79 & 827 & 28,71 & 148,00 & 82,10 & 93,08 \\
\hline out/18 & 740 & 600 & 18,92 & 97 & 83,83 & 50,00 & 48,45 & 93,24 \\
\hline nov/18 & 2680 & 1590 & 40,67 & 272 & 82,89 & 81,30 & 70,11 & 96,97 \\
\hline dez/18 & 3300 & 1610 & 51,21 & 1780 & $-10,56$ & 50,40 & 97,17 & 98,47 \\
\hline jan/19 & 1780 & 1100 & 38,20 & 176 & 84,00 & 35,30 & 79,94 & 98,02 \\
\hline fev/19 & 418 & 100 & 76,11 & 124 & $-24,00$ & 27,90 & 77,50 & 93,33 \\
\hline mar/19 & 2420 & 394 & 83,72 & 92 & 76,52 & 7,60 & 91,78 & 99,69 \\
\hline
\end{tabular}

Fonte: Autores (2020).

Figura 22 - Concentrações de NA após as etapas de tratamento do lixiviado.

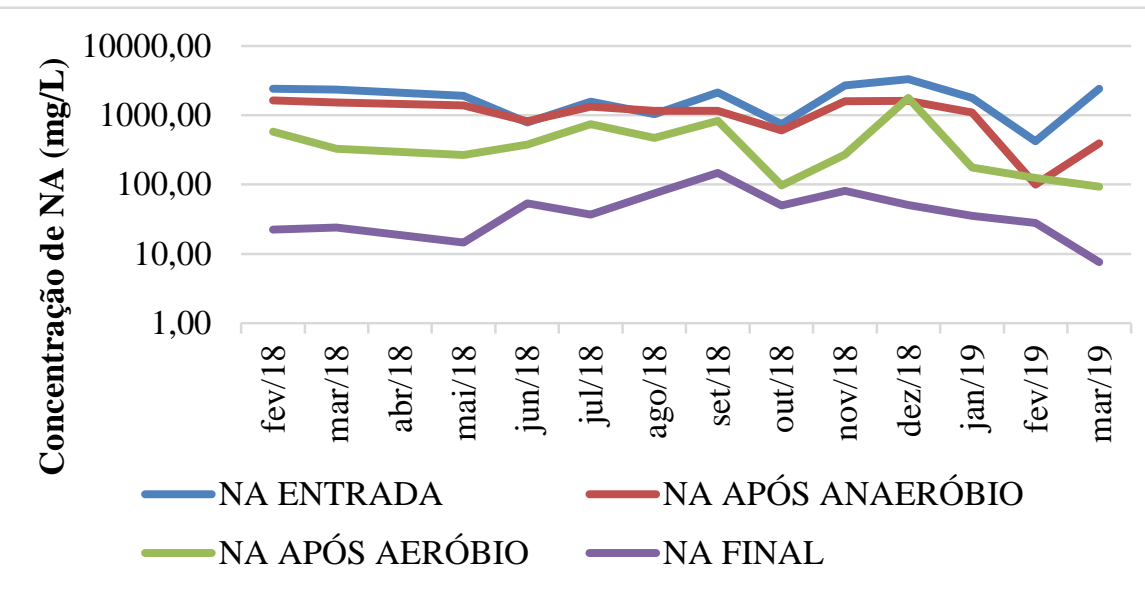

Fonte: Autores (2020). 
Observando a Tabela 4 e a Figura 22, é possível perceber as limitações do processo anaeróbio para remoção das concentrações de nitrogênio amoniacal, com uma eficiência média inferior a $35 \%$ e concentrações finais superiores a $1.000 \mathrm{mg} / \mathrm{L}$. Como já citado no presente estudo, para aterros com certo tempo de operação, os processos biológicos (anaeróbios e aeróbios) são limitados para a remoção de concentrações elevadas de nitrogênio amoniacal.

Em contrapartida, no processo biológico aeróbio, a remoção de nitrogênio amoniacal alcançou eficiências melhores, conforme verificado na Tabela 4, que pode ter ocorrido pelo fato de que nesse processo, o nitrogênio amoniacal pode ser utilizado pelas bactérias na nitrificação, por meio da oxidação da amônia em nitrato, diminuindo essa concentração.

Castilhos Jr. et al. (2009) cita que os sistemas de lagoas apresentam dificuldades na remoção desses compostos refratários, que ocasionam elevadas cargas de Nitrogênio amoniacal, e que dificilmente atingem aos limites exigidos pelos órgãos ambientais. De fato, as cargas finais obtidas após esses processos são superiores a $400 \mathrm{mg} / \mathrm{L}$, enquanto que o limite estabelecido pela Resolução CONAMA 430/2011 é de 20 mg/L.

Com a utilização das outras etapas de tratamento, a remoção de nitrogênio amoniacal alcançou eficiências, que chegam a valores superiores a 90\%. Como já foi citado, SteinerFerreira, Scheer e Braga (2015) obtiveram eficiência de 34\% na remoção de Nitrogênio amoniacal em lixiviado pré-tratado, para o lixiviado bruto essa eficiência foi menor, ressaltando a importância dos processos biológicos que configuram diminuição das cargas poluentes para os processos físico-químicos posteriores. Kargi e Pamukoglu (2004) também utilizaram o carvão ativado e zeólita como adsorventes obtendo eficiências de $30 \%$ e $40 \%$, respectivamente, para remoção de nitrogênio amoniacal. Maurício (2014) no Aterro de Gericinó/RJ utilizou nanofiltração que removeu de forma satisfatório a DQO (73\%), porém não foi tão eficiente para remoção de Nitrogênio Amoniacal, sendo que posteriormente, utilizando filtração com zeólita ele obteve uma eficiência de para remoção de NA. Nesse sentido, essa etapa do sistema deve ter grande relevância para remoção das concentrações de nitrogênio amoniacal no aterro sanitário de Maceió.

Na Figura 23 é apresentada a contribuição da etapa biológica do sistema e da etapa físico-química na eficiência global do sistema para remoção de NA. 
Figura 23 - Contribuição do processo biológico e físico químico na eficiência global do sistema para remoção de NA.

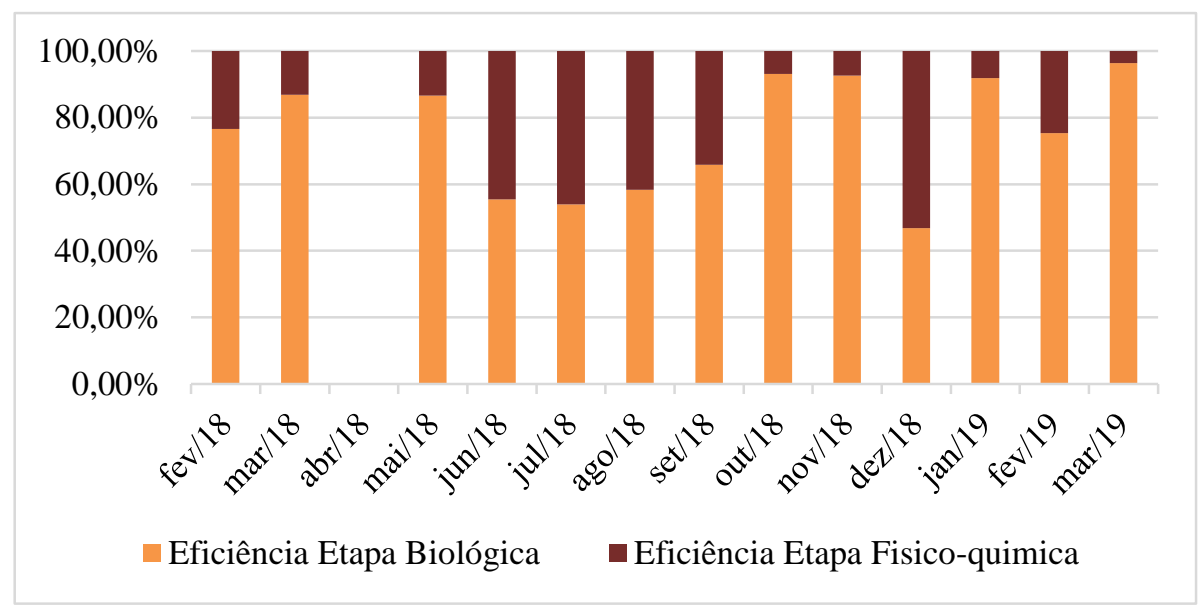

Fonte: Autores (2020).

Analisando a Figura 23, os processos biológicos constituídos de lagoa anaeróbia, lagoa pré-aerada e lagoa aerada da ETE contribuíram em média em 75,42\% para a eficiência global do sistema, os processos físico-químicos de coagulação, floculação, decantação, filtração (carvão ativado e zeólita) e nanofiltração em média de 24,58\%. Apesar das concentrações finais de NA serem elevadas após o processo biológico, essas etapas constituíram de um papel importante para a remoção do NA nas etapas posteriores.

Reis (2014) destaca que nos processos biológicos, a remoção de nitrogênio amoniacal ocorre tanto pela assimilação dos microrganismos quanto ao processo de nitrificação, que é realizado pelas bactérias nitrificantes, que convertem o nitrogênio amoniacal em nitritos e nitratos, que ainda podem ser convertidos a nitrogênio gasoso, através da desnitrificação.

Mesmo com as altas eficiências alcançadas, apenas no último mês analisado (mar/19), a concentração de nitrogênio amoniacal atendeu ao estabelecido pela Resolução CONAMA 430/2011, bem como a outorga de lançamento. Cabe ressaltar que justamente nesse mês, as eficiências dos sistemas anaeróbio e aeróbio foram relevantes, de 83,72\% e 76,52\%, respectivamente, o que pode ter contribuído para uma melhor eficiência das etapas posteriores.

De forma global, o sistema utilizado apresentou eficiência média de 96,44\%, indicando que todos esses processos combinados foram vantajosos para remoção de nitrogênio amoniacal presente no lixiviado. É interessante avaliar as eficiências após a etapa de adsorção e nanofiltração, visando verificar a atuação de cada sistema no tratamento do lixiviado. 


\section{Conclusão}

Quanto ao tratamento do lixiviado gerado no aterro sanitário de Maceió, constatou-se muitas variações nas eficiências obtidas durante os períodos, o que demonstra a complexidade no tratamento do lixiviado, especialmente em um aterro em operação, necessitando da adoção de melhorias ao longo do tempo, a fim de obter melhores resultados. Verificou-se evolução significativa na remoção das concentrações de DBO, DQO e Nitrogênio Amoniacal com as modificações realizadas em cada período. Especificamente com o sistema atualmente implantado, obteve-se eficiência média de $98,79 \%, 95,45 \%$ e 93,42\% para remoção de DBO, DQO e Nitrogênio Amoniacal.

Quando da avaliação por etapa de tratamento, a utilização de filtração com carvão ativado e zeólita, e a etapa de nanofiltração se mostraram essenciais, especialmente pelo fato da redução da relação DBO/DQO, limitar a ação dos processos biológicos. Esses processos obtiveram eficiência média de remoção de $97,30 \%, 90,49 \%$ e $84,28 \%$ para DBO, DQO e Nitrogênio Amoniacal, respectivamente. As eficiências nas lagoas anaeróbias e aeróbias sofreram muitas variações, o que pode indicar influência de outros fatores, tais como, $\mathrm{pH}$, temperatura, TDH e que devem ser melhor analisados.

De toda forma, os processos biológicos se mostraram necessários para eficiência global do sistema. Reiterando a necessidade da utilização de processos combinados para o tratamento de lixiviados de aterros sanitários, principalmente com idades mais avançadas. Porém, apenas no último mês analisado o parâmetro Nitrogênio Amoniacal atingiu o estabelecido pela Resolução CONAMA 430/2011 e a outorga de lançamento, o que acarreta na necessidade da verificação da eficiência posterior as outras etapas do sistema, a fim de proporcionar adequações em alguma destas etapas, além de verificar as eficiências de modo individual, visando o lançamento do efluente no corpo hídrico dentro dos padrões estabelecidos ou outras alternativas, tais como o reuso do efluente tratado para fins de lavagem de veículos e equipamentos na unidade, lavagem de áreas comuns, irrigação de áreas verdes, visando valorização de práticas sustentáveis e necessidade de utilização de fontes alternativas de água.

\section{Referências}

Abbas, A. A.; Jingsong, G.; Ping, L. Z.; Ya, P. Y.; Al-Rekabi, W. S. (2009). Review on landfill leachate treatments. American Journal of Applied Sciences, 6(4), 672-684. 
Albuquerque, E. M. (2012). Avaliação do tratamento combinado de lixiviado de aterro sanitário e esgoto sanitário em sistema de lodos ativados. Tese de Doutorado. Universidade de São Paulo.

Associação Brasileira de Normas Técnicas - ABNT. (2004). NBR 10004. Resíduos sólidos Classificação. Norma Técnica. Rio de Janeiro, 71p.

Castilhos Junior, A. B., Fernandes, F., Lange, L., Lopes, D., Costa, R., Silva, S., ... \& Moravia, W. (2009). Tratamento de Lixiviados de Aterro em Sistema de Lagoas. GOMES, LP Estudos de Caracterização e Tratabilidade de Lixiviados de Aterros Sanitários para as Condições Brasileiras. PROSAB, 140-171.

Steiner-Ferreira, P. A., Scheer, A., \& Braga, M. (2015). Estudo do equilíbrio da adsorção de nitrogênio amoniacal de lixiviado de aterro sanitário em zeólita. Blucher Chemical Engineering Proceedings, 1(2), 15965-15972.

Karg1, F., \& Pamukoglu, M. Y. (2004). Adsorbent supplemented biological treatment of pretreated landfill leachate by fed-batch operation. Bioresource technology, 94(3), 285-291.

Kirmizakis, P., Tsamoutsoglou, C., Kayan, B., \& Kalderis, D. (2014). Subcritical water treatment of landfill leachate: Application of response surface methodology. Journal of environmental management, 146, 9-15.

Li, L., Li, Z., Liu, D., \& Song, K. (2020). Evaluation of partial nitrification efficiency as a response to cadmium concentration and microplastic polyvinylchloride abundance during landfill leachate treatment. Chemosphere, 125903.

Lins, E. A. M. (2011). Proposição e avaliação de um sistema experimental de processos físicos e químicos para tratamento de lixiviado. Tese de Doutorado. Universidade Federal de Pernambuco, Departamento de Engenharia Civil. Pernambuco, Recife. 278p.

Jordão, E. P., \& Pessôa, C. A. (2014) Tratamento de esgotos domésticos. 7. ed. Rio de Janeiro: Associação Brasileira de Engenharia Sanitária e Ambiental. 1050 p. 
Maia, I. S., Restrepo, J. J. B., Castilhos Junior, A. B. D., \& Franco, D. (2015). Avaliação do tratamento biológico de lixiviado de aterro sanitário em escala real na Região Sul do Brasil. Engenharia Sanitaria e Ambiental, 20(4), 665-675.

Maurício, R. G. (2014) Tratamento de lixiviado de aterro sanitário utilizando processos de separação de membranas e zeólita natural. Dissertação de Mestrado. Universidade Federal do Rio de Janeiro.

Oliveira, S. D., \& Pasqual, A. (2004). Avaliação de parâmetros indicadores de poluição por efluente líquido de um aterro sanitário. Engenharia sanitária e ambiental, 9(3), 240-249.

Reis, B. G. (2014). Avaliação da eficiência de processos avançados na remoção de toxicidade de lixiviado de aterro sanitário.

Renou, S., Givaudan, J. G., Poulain, S., Dirassouyan, F., \& Moulin, P. (2008). Landfill leachate treatment: Review and opportunity. Journal of hazardous materials, 150(3), 468-493.

Resolução CONAMA n 430, de 13 de maio de 2011. Dispõe sobre condições e padrões de lançamento de efluentes, complementa e altera a Resolução $n^{o}$ 357, de 17 de março de 2005, do Conselho Nacional do Meio Ambiente - CONAMA. Recuperado de: http://www2.mma.gov.br/port/conama/legiabre.cfm?codlegi=646

Silva, N. S. C. (2017) Avaliação do Processo de nanofiltração integrado ao biorreator com membranas inoculado com leveduras para tratamento de lixiviado de aterro sanitário. Dissertação de mestrado, Universidade Federal de Minas Gerais.

Souto, G. D. B. (2009) Lixiviado de aterros sanitários brasileiros - estudo de remoção no nitrogênio amoniacal por processo de arraste com ar ("stripping”). Tese de doutorado, Universidade de São Paulo. São Carlos, SP, Brasil.

Von Sperling, M. (1996). Princípios básicos do tratamento de esgotos. Departamento de Engenharia Sanitária e Ambiental, Universidade Federal de Minas Gerais. 
Youcai, Z., \& Ziyang, L. (2016). Pollution control and resource recovery: municipal solid wastes at landfill. Butterworth-Heinemann.

Wojciechowska, E. (2017). Potential and limits of landfill leachate treatment in a multi-stage subsurface flow constructed wetland-evaluation of organics and nitrogen removal. Bioresource technology, 236, 146-154.

Zegzouti, Y., Boutafda, A., El Fels, L., El Hadek, M., Lebrihi, A., Bekkaoui, F., \& Hafidi, M. (2019). Qualidade e quantidade de lixiviados com diferentes idades e operações em clima semiárido. Desalin. Água. Treat, 152, 174-184.

\section{Porcentagem de contribuição de cada autor no manuscrito}

Liz Geise dos Santos Araújo - 30\%

Alison de Souza Norberto - 25\%

Riadny Patrícia de Souza Ferreira - 25\%

Maria Odete Holanda Mariano - 10\%

Nélia Henriques Callado - 10\% 